UNIVERSIDADEESTADUAL PAULISTA “JÚLIO DEMESQUITA FILHO”

FACULDADE DE CIÊNCIAS AGRONÔMICAS

CÂMPUS DE BOTUCATU

\title{
ESTUDO DE ILHAS DE CALOR NO MUNICÍPIO DE PIRATININGA/SP, POR MEIO DE DADOS ORBITAIS DO LANDSAT 5 SENSOR TM.
}

NATHALIA MARIA SALVADEO FERNANDES PARIZOTO

Dissertação apresentada à Faculdade de Ciências da UNESP - Campus de Botucatu, para obtenção do título de Mestre em Agronomia (Energia na Agricultura)

BOTUCATU - SP

Dezembro - 2013 
UNIVERSIDADEESTADUAL PAULISTA “JÚLIO DEMESQUITA FILHO” FACULDADE DE CIÊNCIAS AGRONÔMICAS CÂMPUS DE BOTUCATU

\section{ESTUDO DE ILHAS DE CALOR NO MUNICÍPIO DE PIRATININGA/SP, POR MEIO DE DADOS ORBITAIS DO LANDSAT 5 SENSOR TM.}

\section{NATHALIA MARIA SALVADEO FERNANDES PARIZOTO}

Orientador: PROF. DR. SÉRGIO CAMPOS

Dissertação apresentada à Faculdade de Ciências da UNESP - Campus de Botucatu, para obtenção do título de Mestre em Agronomia (Energia na Agricultura)

BOTUCATU - SP

Dezembro - 2013 
FICHA CATALOGRÁFICA ELABORADA PELA SEÇÃO TÉCNICA DE AOUISIÇÃO E TRATAMENTO DA INFORMAÇÃ̃O - SERVIÇO TÉCNICO DE BIBLIOTECA E DOCUMENTAÇẤO - UNESP - FCA - LLAGEADO - BOTUCATU (SP)

Parizoto, Nathalia Maria Salvadeo Fernandes, 1985-

P234e Estudo de ilhas de calor no município de Piratininga/SP, por meio de dados orbitais do Landsat 5 sensor TM / Nathalia Maria Salvadeo Fernandes Parizoto. - Botucatu : [s.n.], 2013

ix, $41 \mathrm{f}$. : tabs., ils. color., fots. color.

Dissertação (Mestrado) - Universidade Estadual Paulista, Faculdade de Ciências Agronômicas, Botucatu, 2013

Orientador: Sérgio Campos

Inclui bibliografia

1. Ilha de calor urbana. 2. Geoprocessamento. 3. Arborização das cidades. 4. Gestão pública. I. Campos, Sérgio. II. Universidade Estadual Paulista "Júlio de Mesquita Fi1ho" (Campus de Botucatu). Faculdade de Ciências Agronômicas. III. Título. 
UNIVERSIDADE ESTADUAL PAULISTA "JÚLIO DE MESQUITA FILHO"

FACULDADE DE CIÊNCIAS AGRONÔMICAS

CÂMPUS DE BOTUCATU

CERTIFICADO DE APROVAÇÃO

TÍTULO: "ESTUdO DE ILHAS DE CALOR NO MUNICÍPIO DE PIRATININGA/SP, POR MEIO DE DADOS ORBITAIS DO LANDSAT 5 SENSOR TM".

ALUNA: NATHALIA MARIA SALVADEO FERNANDES PARIZOTO

ORIENTADOR: PROF. DR. SÉRGIO CAMPOS

Aprovado pela Comissão Examinadora

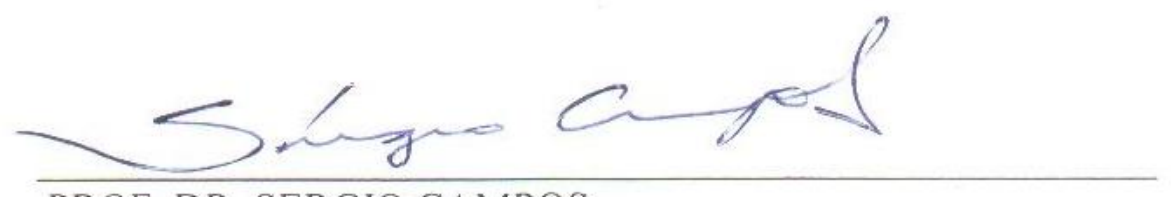

PROF. DR. SERGIO CAMPOS
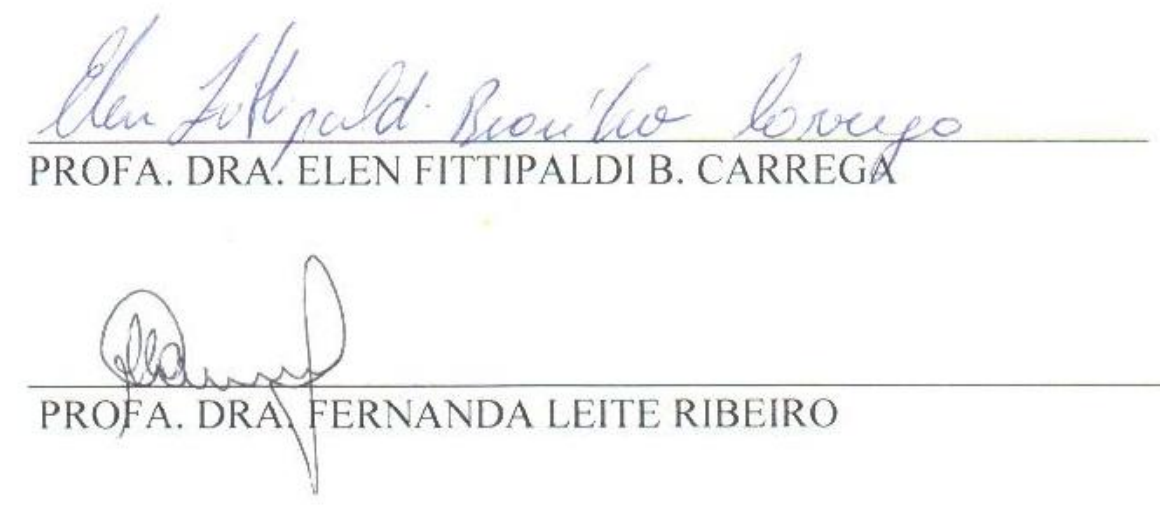

Data da Realização: 19 de dezembro de 2013. 
Aos meus pais Ruth e Laércio.

DEDICO

Ao meu marido Luis Eugênio.

OFEREÇO 


\section{AGRADECIMENTO}

Ao Professor Doutor Sérgio Campos, agradeço pela oportunidade, confiança e orientação para a realização deste trabalho e acima de tudo, pela amizade consolidada com a convivência. 


\section{AGRADECIMENTO}

À Deus e Nsa. Senhora, que sempre iluminaram meus caminhos e me deram forças para continuar minha jornada;

À Faculdade de Ciências Agronômicas/UNESP, Campus de Botucatu-SP e ao Programa de Pós Graduação Energia na Agricultura, pela oportunidade de realizar este trabalho;

A Prof. Dra. Elen Fittipaldi Brasilio Carrega e ao Prof. Dr. Zacarias Xavier de Barros, membros da Banca de Qualificação, pelas sugestões e pelas palavras de incentivo ao trabalho;

A Prof. Dra. Elen Fittipaldi Brasilio Carrega e Prof. Dra. Fernanda Leite Ribeiro, membros da Banca Examinadora da Defesa da Dissertação, pela atenção e dedicação dispensada e pela grande contribuição para melhoria deste trabalho;

À Prefeitura Municipal de Piratininga, que disponibilizou diversos materiais e pelas informações concedidas;

À todos os profissionais e amigos que contribuíram direta ou indiretamente para a realização deste trabalho. 


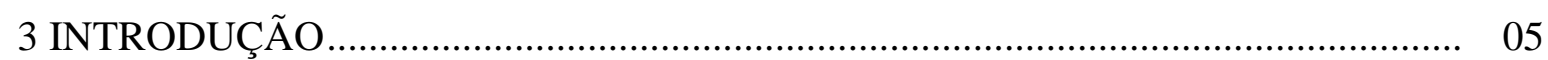

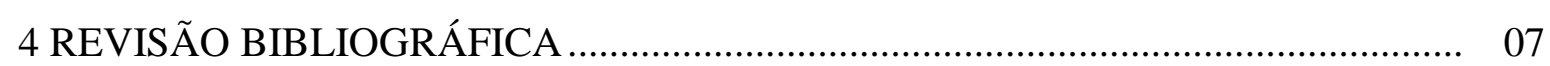

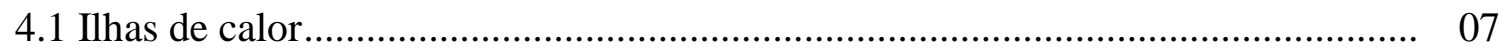

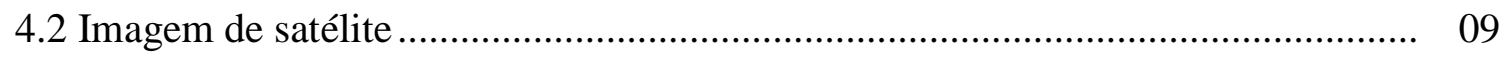

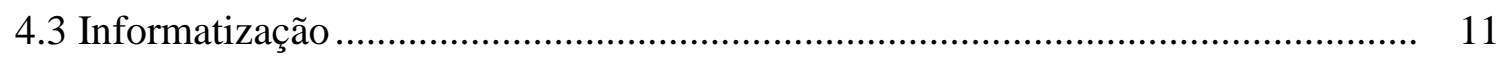

4.4 Arborização urbana.................................................................................. 12

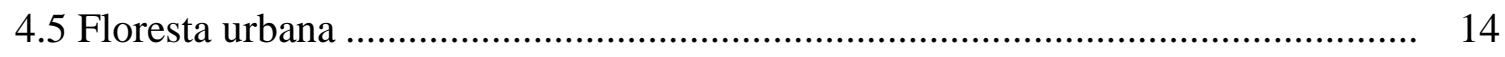

4.6 Gestão pública ambiental......................................................................... 15

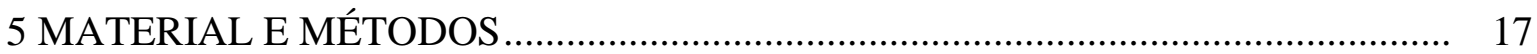

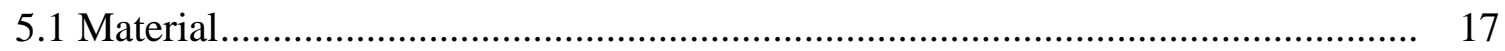

5.1.1 Área de estudo .......................................................................... 17

5.1.2 Programas computacionais utilizados ................................................. 18

5.1.3 Obtenção de Temperatura..................................................................... 18

5.1.4 Obtenção de imagem ......................................................................... 19

5.1.5 Levantamento de áreas verdes e setorização do município ........................... 19

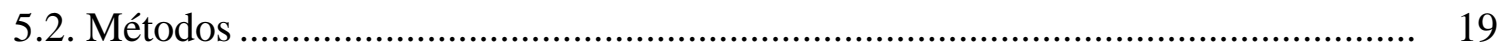

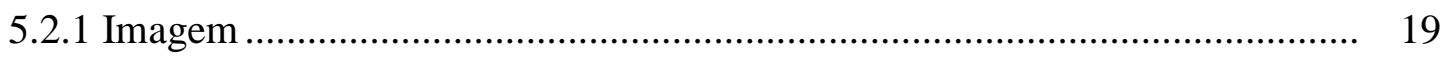

5.2.2 Temperatura aparente da superfície ..................................................... 21

5.2.3 Áreas verdes .............................................................................. 22

5.2.4 Levantamento de temperatura em campo................................................ 22

5.1.4 Classe de uso do solo ............................................................................. 22

5.7.6 Divisão da malha urbana por setores ......................................................... 23

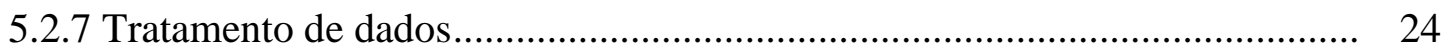

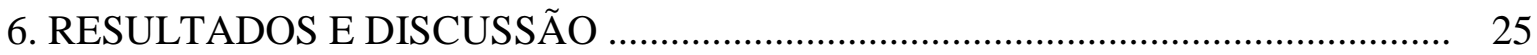

6.1 Desempenho das ilhas de calor.................................................................. 25

6.2 Classificação do solo e temperatura ................................................................ 27

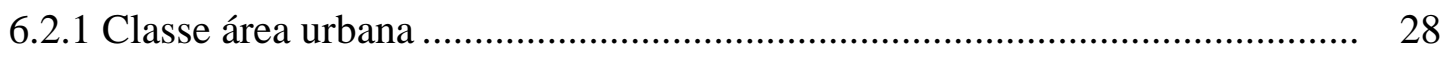

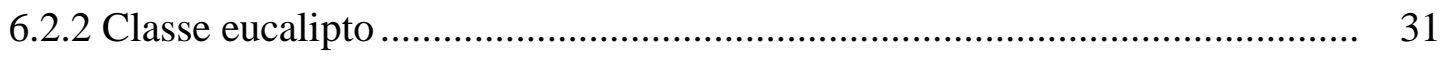

6.2.3 Classe mata nativa ................................................................................... 31 


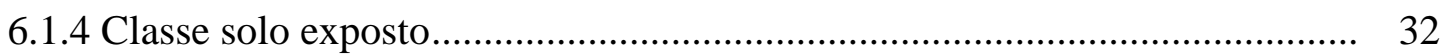

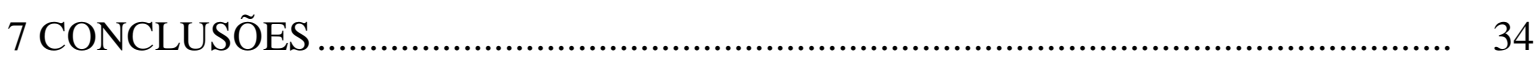

8 REFERÊNCIAS BIBLIOGRÁFICAS .............................................................. 35 


\section{LISTA DE FIGURAS}

Figura 1: Localização do Município de Piratininga .................................................... 18

Figura 2: Imagem bruta do mosaico dos pontos 75 e 76 da orbita 221 banda 6 ........... 20

Figura 3: Fluxograma das etapas de metodologia .................................................... 21

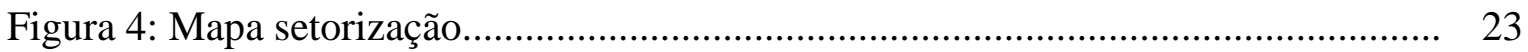

Figura 5: Temperatura aparente da superfície do Município de Piratininga .................. 25

Figura 6: Histograma da temperatura aparente do Município....................................... 26

Figura 7: Polígono dos setores da área urbana do Município de Piratininga ................. 27

Figura 8: Classificaçãa de uso do solo utilizando imagem Geo Eye............................. 27

Figura 9: Detalhe da temperatura aparente da área urbana ....................................... 28

Figura 10: Pontos de levantamento de temperatura em campo ..................................... 30

Figura 11: Ponto da classe eucalipto ..................................................................... 31

Figura 12: Ponto da classe mata nativa .................................................................. 32

Figura 13: Destaque da classe solo exposto ............................................................ 33 


\section{LISTA DE TABELAS}

Tabela 1: Características e aplicação do sensor TM/LANDSAT 5 .............................. 10

Tabela 2: Setores do Município de Piratininga ............................................................ 24

Tabela 3: Coordenadas das classes de solo ............................................................. 28

Tabela 4: Índice de Cobertura Vegetal ................................................................... 29

Tabela 5: Levantamento com termo-higrômetro ......................................................... $\quad 30$ 


\section{RESUMO}

Com a ocupação massiva da malha urbana e as atividades decorrentes do crescimento desordenado dessas áreas, ocorre uma alteração do clima urbano, tornando-o insalubre. Um dos fatores que contribui para a má qualidade de vida em decorrência deste fato são as ilhas de calor que consiste no acúmulo de calor na superfície e eleva a temperatura nas cidades. A vegetação urbana constituída de arborização urbana, bosques e áreas verdes, têm como função minimizar este efeito. Para conciliar esses fatores o trabalho tem como objetivo levantar os dados de temperatura de superfície através de imagens de satélite, LANDSAT 5 captada no dia 18/12/2012 dos pontos 75 e 76, órbita 221, banda 6 e levantamento in loco com termo-higrômetro, com posse dos dados, cruzar com o levantamento vegetativo realizado e proporcionar uma visão de gestão para melhorar o microclima do município em estudo. O sensoriamento remoto e o sistema de informação geográfica permitem a avaliação de diferentes temperaturas da superfície terrestre. A área reduzida do Município e a baixa resolução do sensor utilizado dificultaram a análise de temperatura da área urbana sendo necessário o uso de outros programas para auxiliar na interpretação de dados. A cobertura de vegetação na área urbana interfere diretamente na diminuição da temperatura melhorando o micro-clima urbano. As diferentes coberturas da superfície analisada também interferem na temperatura aparente. Entre as classes estudas a classe cultivo de eucalipto e mata nativa apresentaram temperatura aparente amena em torno de $22.0^{\circ} \mathrm{C}$ e o solo exposto a maior temperatura aparente entre $37.0^{\circ} \mathrm{C}$. Os setores 4,5 e 7 apresentam uma média de temperatura de $27,0^{\circ} \mathrm{C}$ sendo os setores com temperatura mais amena devido a área de cobertura vegetal. A 
diferença de temperatura nos setores $9,10,12$ e 13 de $32.0^{\circ} \mathrm{C}$ para $27.0^{\circ} \mathrm{C}$ é devido a existência de áreas verdes como praças. As altas temperaturas do levantamento em campo com termo-higrômetro na área urbana, em média de $35.0^{\circ} \mathrm{C}$ é devido ao clima que seco e a ausência de vento além da rugosidade e edificação da superfície.

Palavras-chave: Ilhas de Calor, Geoprocessamento, Arborização Urbana; Gestão Pública. 
STUDY OF HEAT ISLAND IN THE CITY OF PIRATININGA / SP THROUGH DATA OF ORBITAL LANDSAT 5 TM SENSOR. Botucatu, 2013. 42 p. Dissertação (Mestrado em Agronomia/Energia na Agricultura) - Faculdade de Ciências Agronômicas, Universidade Estadual Paulista.

Author: NATHALIA MARIA SALVADEO FERNANDES PARIZOTO

Adviser: Ph. D. SÉRGIO CAMPOS

\section{SUMMARY}

With the massive occupation of the urban and activities arising from the uncontrolled growth of these areas, a change occurs in the urban climate, making it unhealthy. One factor that contributes to poor quality of life due to this fact are the islands of heat which consists in the accumulation of surface heat and raises the temperature in the cities. The vegetation consists of urban greening, urban forests and green areas, have the function to minimize this effect. To reconcile these factors work aims to collect data on surface temperature by satellite images, LANDSAT 5 captured on 18/12/2012 point 75 e 76, orbits 221 , band 6 and on-site survey with thermo-hygrometer, with possession of the data, crossing to the survey conducted vegetative and provide a management vision to improve the microclimate of the city under study. The remote sensing and the geographic information system allow the evaluation of different earth surface temperatures. The municipality reduced area and the low resolution detector used makes the temperature analyzes at the urban area more difficult requiring the use of other programs to assist in the data interpretation. The vegetation coverage at urban area directly affects in the temperature decreasing improving the urban micro-climate. The different analyzed surface coverage also affects the apparent temperature. Among the studied ranks, the eucalyptus cultivation and native forest rank show mild apparent temperature around $22.0^{\circ} \mathrm{C}$ and the solo exposed to the higher apparent temperature around $37.0^{\circ} \mathrm{C}$. The 4,5 and 7 sectors present a $27,0^{\circ} \mathrm{C}$ temperature average, and these are the sectors with the milder temperature due to the vegetation coverage area. The temperatures difference at the $9,10,12$ and 13 sectors from $32.0^{\circ} \mathrm{C}$ to $27.0^{\circ} \mathrm{C}$ is due to the existing green areas, such as squares. The site survey high temperatures measured by thermo-hygrometer are around $35.0^{\circ} \mathrm{C}$ due to the dry weather and the lack of windy besides the surface rugosity and building. 
Keywords: Heat Islands, GIS, Urban Forestry; Public Management. 


\section{INTRODUÇÃO}

Segundo a Organização das Nações Unidas (ONU) hoje a população mundial soma 7,2 bilhões/ano de pessoas, sendo que mais de 50\% encontra-se locado em área urbana. As atividades decorrentes do crescimento urbano e industrial descontrolado ocasionam um ambiente insalubre nas cidades, devido às alterações na pureza do ar e climáticas. Assim, os benefícios ambientais da arborização se tornam mais necessários à saúde ambiental do ecossistema urbano, quanto maior o nível de urbanização.

A vegetação nas cidades surge normalmente como jardins e parques, ocupando diferentes áreas com aspectos e função variada. (ALMEIDA, 2006).

A arborização urbana bem com as áreas cobertas por vegetação (floresta urbana) contribui não apenas para a melhoria do Clima, mas também para o controle da poluição atmosférico filtrando partículas, retendo poeira e fumaça e proporcionando conforto acústico em alguns casos (JUNIOR, 2009). No entanto varias cidades brasileiras não possuem adequado planejamento de arborização urbana não atingindo assim o seu fundamento. (ALMEIDA, 2009)

Atualmente com o avanço das geotecnologias e dos dados do sensoriamento remoto, como o aumento da resolução de imagens de satélite, obtem-se 
diversas informações do ambiente terrestre. Uma das informações contidas nas imagens é a temperatura aparente da superfície, através da captação da energia eletromagnética emitida por determinado ambiente ou objeto.

A tecnologia junto com os avanços em geoprocessamento fornece ao poder público novos horizontes de gestão, com a utilização de imagens de satélite e levantamento de campo é possível organizar e distribuir a arborização urbana, áreas verdes e praças de forma propiciar um ambiente com temperaturas agradáveis, alem de outros benefícios que acompanham a linha de benefícios.

Além da rápida obtenção de dados e disponibilidade gratuitas das imagens de satélite, o uso do sensoriamento remoto é crescente devido aos registros históricos disponíveis, oferecendo dados importantes para a análise temporal do desenvolvimento das ilhas de calor.

Os Sistemas de Informação Geográficos (SIGs) são ferramentas fundamentais para aplicação das técnicas de processamento digital das imagens, possuem diversos algoritmos e dentre eles um capaz de transformar os dados do infravermelho termal em temperatura aparente da superfície, imprescindíveis para interpretação destes dados.

O objetivo deste trabalho é utilizar o sensoriamento remoto e a imagem de satélite para avaliar a temperatura confrontando a existência de ilhas de calor e arborização urbana, utilizando imagens de satélite e levantamento de arborização urbana realizado anteriormente, a fim de auxiliar na gestão de uso do solo urbano visando a melhoraria do micro-clima. 


\section{REVISÃO BIBLIOGRÁFICA}

\subsection{Ilhas de calor}

De todas as modificações climáticas produzidas pela cidade, a mais evidente e estudada consiste no fenômeno chamado de ilha de calor. É um fenômeno próprio das cidades, resultante do processo de urbanização e características peculiares ao meio urbano (BARBIRATO, SOUZA e TORRES, 2007). O fenômeno da ilha de calor vem sendo observado em cidades em todo o mundo (GARTLAND, 2010).

Configura-se como um fenômeno decorrente do balanço de energia no espaço urbano, que se caracteriza através do acúmulo de calor nas superfícies e conseqüente elevação da temperatura do ar (BARBIRATO, SOUZA e TORRES, 2007).

Coltri (2006) evidencia que uma das maiores modificações causadas pela urbanização é a alteração das características térmicas da superfície pelo excesso de edificações e materiais de construção quando comparado às áreas verdes. Tais materiais aumentam a absorção de energia bem como impermeabilizam a superfície. Além disso, o aumento da rugosidade urbana altera padrões de circulação do ar, e as atividades antrópicas, por sua vez, alteram a atmosfera urbana pela adição de calor e material particulado. 
Segundo Lombardo (1985), este fenômeno reflete a interferência do homem na dinâmica dos sistemas ambientais. A distribuição das isotermas nas cidades mostra uma tendência para o aumento da temperatura da periferia em direção ao centro.

Farias (2006) citado por Primavesi, Arzabe e Pereira (2007) afirma que a intervenção da sociedade no clima é feita a partir das escalas inferiores, onde o livre arbítrio do homem é decisivo na construção de climas artificiais, podendo, pela ação cumulativa afetar até escalas maiores como a regional.

Oke (1974) citado por Coltri (2006) traçou o perfil das ilhas de calor de grandes centros urbanos, descrevendo que o local com maior atividade antrópica, normalmente o centro, se caracteriza por ser mais quente do que os bairros residenciais e periféricos. Esse perfil foi chamado de perfil clássico das ilhas de calor.

O perfil clássico das ilhas de calor já foi estudado por diversos autores, como Lombardo (1985) que observou diferença de temperatura entre área urbana e rural em São Paulo na ordem de $10^{\circ} \mathrm{C}$.

Fialho (2009) divide as ilhas de calor em três tipos: a) vertical, divida em Intra urbana (da superfície até o telhado das construções) medida em micro escala e Limite urbano (acima do nível dos telhados) medida em mesoescala e tem como interferência a poluição, velocidade do vento e rugosidade urbana; b) de superfície, usa como medidor de temperatura o sensoriamento remoto e tem como resultado a temperatura aparente da superfície; c) atmosférica, onde a temperatura do ar é medida em secções móveis ou pontos fixos, levando em consideração a cobertura da terra e o tipo de uso do solo.

Mesmo municípios que não são consideradas grandes metrópoles, podem ter diferença entre temperatura rural e urbana comparável a de grandes centros urbanos como São Paulo, como foi observado por Coltri (2007), em estudo de ilha de calor em Piracicaba, SP, outro exemplo de variação considerável de temperatura foi constatado por Mashiki (2012) no município de Botucatu, SP com temperatura máxima de $35^{\circ} \mathrm{C}$ na área urbana e $19^{\circ} \mathrm{C}$ na área rural.

Também podem ocorrer ilhas de calor em áreas rurais, se estiverem degradadas, secas, mas elas podem não ocorrer em áreas urbanas, se estiverem adequadamente arborizadas e com água disponível no solo para a evapotranspiração (PRIMAVESI, ARZABE e PEREIRA, 2007). 
Considerando a magnitude das ilhas de calor, muitos são os mecanismos e fatores que contribuem para a sua formação e intensidade desde sua localização geográfica até as condições climatológicas do dia. Há também fatores relacionados às características específicas da cidade como o tamanho da cidade, a densidade da população, o dia da semana, a cultura local (COLTRI, 2007).

Costa (2009) analisando diferenças de temperatura no município de Ilha Solteira - SP constatou que entre classes de uso e ocupação do solo existe variação térmica e que a classe que apresentou os menores intervalos de temperatura foi a classe vegetação. As maiores temperaturas observadas $\left(41\right.$ e $\left.44^{\circ} \mathrm{C}\right)$, correspondem às classes de uso do solo com edificações e/ou pavimentada, já as menores temperaturas $\left(20-23^{\circ} \mathrm{C}\right)$, estão localizadas no zoológico e no Parque da Mantigueira, que compreendem áreas com maior índice de vegetação.

\subsection{Imagem de satélite:}

As imagens de satélite são obtidas por equipamentos (satélites artificiais) lançados à órbita da Terra por foguetes e que através de sensores acoplados fazem a leitura da superfície na terra formando imagem. O satélite Landsat 5 foi lançado em 1984 portando o sensor Thematic Mapper (TM). Este sensor possui 7 bandas que captam diferentes faixas de espectro sendo utilizada para varias finalidades como vemos na Tabela 01. 
Tabela 01. Características e aplicações do sensor TM/LANDSAT - 5 .

\begin{tabular}{|c|c|c|c|c|}
\hline Banda & $\begin{array}{c}\text { Faixa } \\
\text { Espectral }\end{array}$ & $\begin{array}{l}\text { Região do } \\
\text { Espectro }\end{array}$ & $\begin{array}{c}\text { Resolução } \\
\text { Espacial } \\
(\mathbf{m} \times \mathbf{m})\end{array}$ & Principais Aplicações \\
\hline 1 & $0,45-0,52$ & Azul & 30 & $\begin{array}{l}\text { Oceanografia; } \\
\text { Diferenciação entre solo e } \\
\text { vegetação; } \\
\text { Diferenciação entre vegetações } \\
\text { coniferas e deciduas. }\end{array}$ \\
\hline 2 & $0,52-0,60$ & Verde & 30 & $\begin{array}{l}\text { Reflectância de vegetação verde e } \\
\text { sadia. }\end{array}$ \\
\hline 3 & $0,63-0,69$ & Vermelho & 30 & $\begin{array}{l}\text { Absorção de clorofila; } \\
\text { Diferenciação de espécies vegetais. }\end{array}$ \\
\hline 4 & $0,76-0,90$ & IV/Próximo & 30 & $\begin{array}{l}\text { Levantamento de biomassa; } \\
\text { Delineamento de corpos de água. }\end{array}$ \\
\hline 5 & $1,55-1,75$ & IV/Médio & 30 & $\begin{array}{l}\text { Medidas de umidade de vegetação; } \\
\text { Diferenciação entre nuvens e neve. }\end{array}$ \\
\hline 6 & $10,4-12,5$ & IV/Termal & 120 & $\begin{array}{l}\text { Mapeamento de estresse térmico em } \\
\text { plantas; } \\
\text { Outros mapeamentos térmicos. }\end{array}$ \\
\hline 7 & $2,08-2,35$ & IV/Médio & 30 & Mapeamento hidrotermal \\
\hline
\end{tabular}

Fonte: Barbosa, 2009

Crosta (1993) define ainda que as imagens de satélite possam ser digital ou discreta constituída por um conjunto de celas chamado grid ou malha, cada cela (pixel), possui num mesmo sensor, a mesma medida e também um atributo numérico denominado "Z" (digital number) representado por uma escala de cinza representa a intensidade média da energia magnética refletida ou emitida por uma superfície.

Cada banda termal do Landsat 5 é representada através de uma imagem composta por uma matriz de pixels em 256 tons de cinza (COLTRI, 2006). Cada um dos pixels que compõem a imagem tem um número digital (DN) associado, número esse que corresponde à tonalidade de cinza através do qual é representado e à característica da região (COLTRI, 2006).

As resoluções das imagens são dividas em três tipos: a resolução espacial, definida pela capacidade do sensor de "ver" os objetos na superfície terrestre; a 
resolução espectral, definida pela numero de bandas e comprimento do intervalo de onda utilizado pelo sensor; e a resolução radiométrica, que representa dados pelo sensor através de níveis de cinza. (CROSTA, 1993).

Segundo Florenzano (2002), a obtenção de imagens coloridas é realizada através de sobreposição de filtros de cor primária (azul, verde e vermelho), as imagens obtidas em escala de cinza são sobrepostas a estes filtros coloridos e formam a imagem colorida. O que define a cor da imagem segundo o mesmo autor é a capacidade de refletância do objeto da imagem.

\subsection{Informatização:}

No mundo de hoje dados de pesquisas são disponibilizados a todos os interessados através de uma rede informatizada que disseminados a partir de um banco de dados central. De forma a conservar a lembrança a sociedade desenvolvia a oralidade, da mesma maneira que um matemático necessita colocar no papel para expor suas proposições e transmitir sua memória, a informática vem para ampliar nossa memória e renovar o conhecimento (BORBA, 2000).

Tendo como função a representação, o armazenamento e a distribuição de dados, a bioinformática se encontra dentro do campo biologia computacional que é a aplicação de técnicas analíticas quantitativas à modelagem de sistemas biológicos. Para desenvolver estes sistemas há envolvimento de técnicos que vão da lingüística até ciências da computação (GIBAS e JAMBECK, 2001).

Segundo Gibas e Jambeck (2001), a taxonomia (sec. XVII) foi o primeiro problema apresentado por pesquisadores que encontraram a solução através da informática, por possuir milhões de espécies catalogadas nem o mais exímio dos biólogos possui todas as informações e a forma de ampliá-las foi através de projetos como "Arvore da vida" e banco de dados de taxonomia da NCBI através da informática.

Capron e Johnson (2004) definem software como um conjunto de instruções que orientam o computador a fazer tarefas e produzir resultados desejados, tudo sendo coordenado pelo usuário (pessoa). 
Já para Schwatzman et. al. (1996), o software é a tecnologia essencial a todo segmento (privado, governamental e até mesmo o tecnológico) para sua boa operacionalização.

Sommerville (2005) descreve ainda que o software é mais que um simples programa, é na verdade um universo de documentos e dados de configuração que faz com que o programa funcione corretamente.

Há vários tipos de software como: Gráfico, Texto, Comunicação entre outros sendo cada utilizado para uma tarefa específica. O software que utilizaremos neste estudo é um software de dados e imagem.

A inteligência artificial é fazer com que uma máquina consiga executar habilidades humanas a fim de substituir-nos em algumas atividades (MÓDULO, 2009). Ainda segundo o mesmo autor já é possível ver o uso dessas I.A. em jogos de vídeo game ou ate mesmo num simples corretor de textos.

O conceito da área de inteligência artificial explorado é o de Redes Neurais Supervisionadas, um tipo de construção que simula o cérebro humano segundo algum treinamento.

\subsection{Arborização urbana:}

Segundo Milano (1988) todo conjunto de vegetação arbórea ou em estado natural seja em área pública ou privada é denominada arborização urbana sendo incluídas todas as árvores de ruas, avenidas, parques e todas as áreas verdes.

A arborização urbana adequada, além de reaproximar o homem da natureza (SANTOS e TEIXEIRA, 2001), ameniza os impactos ecológicos no ambiente urbano oriundos da vegetação natural pouca ou ausente, contribuindo para melhoria da qualidade de vida da população. Com o paisagismo é possível introduzir espécies nativas visando a conservação das mesmas. Lorenzi (1998) afirma que o Brasil é o país mais diversificado em espécies da flora global, o que garante uma fenologia distribuída no decorrer das estações do ano, garantindo o paisagismo colorido e alimento a avifauna urbana, mas cerca de $80 \%$ das espécies utilizadas em planos de arborização ainda são de origem exótica. 
A arborização além de embelezar a paisagem urbana exerce influência na melhoria da qualidade ambiental das cidades. As árvores urbanas são capazes de fixar a poeira e os resíduos em suspensão oriundos das atividades industriais e combustão dos veículos circulantes, depurarem bactérias e outros microorganismos, participarem da reciclagem e fixação dos gases, suavizar temperaturas extremas conservando a umidade do solo e melhorando o microclima, reduzir a velocidade do vento, garantir a permeabilidade e a fertilidade do solo influenciando no balanço hídrico e reduzir a poluição sonora (MENEGHETTI, 2003).

A árvore está historicamente presente no ciclo de vida do homem, tendo sido útil para alimentar fogueiras, como utensílio para caça, implemento agrícola e hoje, no cotidiano do homem nas mais diversas formas, porém sua inserção no contexto urbano é recente (SANTOS e TEIXEIRA, 2001). Segawa (1996) apud Andrade (2002) o plantio de árvores, teve início com os Belgas de Antuérpia, durante o século XVIII, que mantinham áreas ornamentadas com árvores. No Brasil, a cidade do Recife foi a primeira a dispor de arborização de rua, em meados do século XVII como herança dos países que já praticavam o paisagismo (SANTOS e TEIXEIRA, 2001).

O século XX constituiu um período de desenvolvimento rompendo as relações homem- natureza. $\mathrm{O}$ crescimento desordenado das cidades impôs a presença da árvore, com os espaços construídos e livres dificultou as condições adequadas ao desenvolvimento da vegetação, que sofre transformações devido as modificações dos elementos naturais como solo, ar, água, clima etc. (SANTOS e TEIXEIRA, 2001).

Para atender as necessidades de manejo de qualquer recurso realiza-se um inventário. No caso da arborização, o inventário possibilita a identificação de pontos estratégicos de plantio ou remoção de árvores, e a definição de espécies adequadas aos pontos determinados, ou seja, fornece subsídios que servirão como base para a implementação de um futuro plano de arborização (MENEGUETTI, 2003).

A fim de subsidiar o planejamento urbano para atingir a melhorias do clima, estes levantamentos vêm sendo feitos em diversas cidades, tais como Santa Maria no Rio Grande do Sul (TEIXEIRA, 1999), Campos do Jordão (ANDRADE, 2002), Vinhedo (HARDER, 2002) e Santos (MENEGUETTI, 2003) no estado de São Paulo que tem seu crescimento associado ao turismo. 


\subsection{Floresta Urbana:}

Após o século XIX surgiu o termo Green Belt (cintura verde) que nada mais é que uma área verde circundando a área urbana impondo limites a expansão urbana, como a intenção do surgimento de corredores verdes pela cidade originada desse cinturão (MAGALHÃES, 1992), o que se tornou o primórdio do termo Floresta Urbana.

Os espaços verdes recebem como definição:

O conjunto de áreas livres, ordenadas ou não, revestidas de vegetação, e que exercem funções de protecção ambiental, integração paisagística ou arquitectónica, e/ou de recreio. Podem afigurar-se das seguintes formas: parques e jardins urbanos, públicos e privados; áreas de integração paisagística e de protecção ambiental de vias e outras infra-estruturas urbanas; taludes e encostas revestidos de vegetação; vegetação marginal dos cursos de água e de lagos; sebes e cortinas de protecção contra o vento ou a poluição sonora; zonas verdes de cemitérios; zonas agrícolas e florestais residuais no interior dos espaços urbanos ou urbanizáveis. Representam uma entidade que engloba a totalidade dos espaços ocupados com vegetação, constituindo o somatório das áreas e trechos naturais integrados ou integráveis no tecido urbano. (FADIGAS 1993 apud ALMEIDA 2006)

O termo floresta urbana foi usado pela primeira vez em um estudo sobre os resultados de um plantio na região metropolitana de Toronto (KONIJNENDIJK, 2003). Segundo Harvey (1985) o termo floresta urbana baseou-se no esquema sistemanatureza e sistema-homem, que é dado como meio ambiente construído e integrado (natureza e artificial) no meso contexto.

O conceito de "floresta urbana" numa visão sistêmica de Jorgensen (1974) era baseado na visão unicamente florestal, já Metzger (2001) numa visão mais atualizada descreve o conceito de integração da biota com a ecologia da paisagem, considerando alem da vegetação, a geografia, a paisagem e a ecologia.

Badiru (2005) descreve que a floresta urbana é um referencial social, político, econômico e arquitetônico, porém devido a limitações de sobrevivência 
impostas pelo ambiente urbano faz com que seja apenas um contato entre pessoa-natureza no dia-a-dia urbano.

$\mathrm{Na}$ área urbana onde há um conjunto de construídos que englobam prédios, asfaltos, calçamentos entre outros, a questão hídrica quando mal planejada se torna um problema, segundo Croft e Baylei (1964) apud Badiru (2006) as florestas auxiliam este componente através da percolação, infiltração entre outros mecanismos que evitam problemas tais como processos erosivos por exemplo.

Esses problemas causam um transtorno na paisagem que reflete a ação do homem uma vez que a sua elaboração é feita através de conhecimentos e culturas já conhecidas (LEITE, 1994). Para Gualtieri (2005), a paisagem é a interação homemecologia que de forma evolutiva contribui para o planejamento político, ambiental, conservacional.

Segundo Badiru (2006), a ocupação urbana desordenada resulta em escassez de água e poluição que são fatores relevantes para a degradação florestal. Porém com a reorganização urbana aplicando os espaços verdes influenciados pela população, denominada floresta (conj. de árvores) e espaço urbano, quando alinhados se tornam imprescindíveis para o desenvolvimento adequado das áreas urbanas.

Silva Filho et.al. (2005) sita que no presente momento não há uma metodologia para avaliação de áreas verdes urbanas, devido a falta de conhecimento que permita a mensuração e proporção dessas áreas, seja elas públicas ou privadas, quanto a distribuição na área urbana, formas de utilizar o espaço entre outros fatores.

\subsection{Gestão pública ambiental:}

O artigo 30 da Constituição Federal prevê que os municípios podem e devem legislar no que couber sobre o meio ambiente de forma local para uma causa global.

CF, art. 30. Compete aos Municípios:

[...]I - Legislar sobre assunto de interesse local;

II - Suplementar a legislação estadual e federal no que couber,[...] 
VIII - Promover no que couber, adequado ordenamento territorial, mediante planejamento e controle do uso do parcelamento e da ocupação do solo urbano.[...] (ANTUNES, 2002)

Desta forma o Município pode legislar não apenas sobre o conteúdo mais também conceitos e procedimentos, que podem incluir desde o executivo, legislativo, equipe técnica pública ou privada e a população local, cooperando por uma causa global.

Ibidem, expõe ainda o artigo $2^{\circ}$ da Lei federal $n^{\circ} 10.257 / 01$ que norteia a administração pública, entre eles há: I garantia do direito as cidades sustentáveis, entendido como direito a terra urbana, à moradia, ao saneamento ambiental... para as presentes e futuras gerações...IV... correção das distorções do crescimento urbano e seus efeitos negativos sobre o Meio Ambiente;...VI ordenação e controle do uso de solo, de forma a evitar:...g) a poluição e a degradação ambiental;.

Alem das diretrizes expostas pela lei um instrumento muito importante é apresentado por Antunes (2002), o Plano Diretor Municipal, que através de suas definições de Zonas e seus meios de expansão, visam à proteção e preservação ambiental. Essas Zonas são definidas como Zona Urbana (ZU), Zona de Expansão Urbana (ZEU), Zona Rural (ZR), Zona de Uso Industrial (ZUI) (aceita instalações de empresas não apenas industriais), Zona de Uso predominantemente Industrial (ZUPI) (área destinada a indústrias que possuem pouco impacto de vizinhança e exige tratamento de efluentes), entre outras.

O Município de Piratininga possui plano diretor, com as delimitações de zoneamento e Lei de uso e ocupação do solo que são base jurídica à proteção dos poucos remanescentes de floresta natural que não foram substituídos por monocultura ao redor do município com o intuito de preservação do meio não apenas da visão ecológica mais também da visão paisagística e de interação homem-ambiente.

Além dos instrumentos acima o município também possui lei e plano de arborização que visam a melhoria na arborização e nas áreas verdes do município. 


\section{MATERIAL E MÉTODOS}

\subsection{Material}

\subsection{1 Área de estudo}

O Município de Piratininga está situado a noroeste do Estado de São Paulo, na latitude sul $22^{\circ} 24^{\prime} 00^{\prime \prime}$ e longitude oeste de Greenwich $49^{\circ} 08^{\prime} 00^{\prime \prime}$.

O Município localiza-se próximo as rodovias Marechal Rondon (SP 300) e Comandante João Ribeiro de Barros (SP 294). Com território de $392 \mathrm{Km}^{2}$, limita-se com os municípios de Bauru (Norte e Nordeste), de Agudos (Sul e Sudeste), de Duartina (Noroeste), de Cabrália Paulista (Oeste) e de Avaí (Norte e Noroeste), como demonstrado na Figura 1.

A classificação climática segundo Koeppen é Aw, mais quentes, tropical chuvoso com inverno seco e mês mais frio com temperatura média superior a $18^{\circ} \mathrm{C}$ e o solo Latossolo Vermelho (CEPAGRI, 2013). 


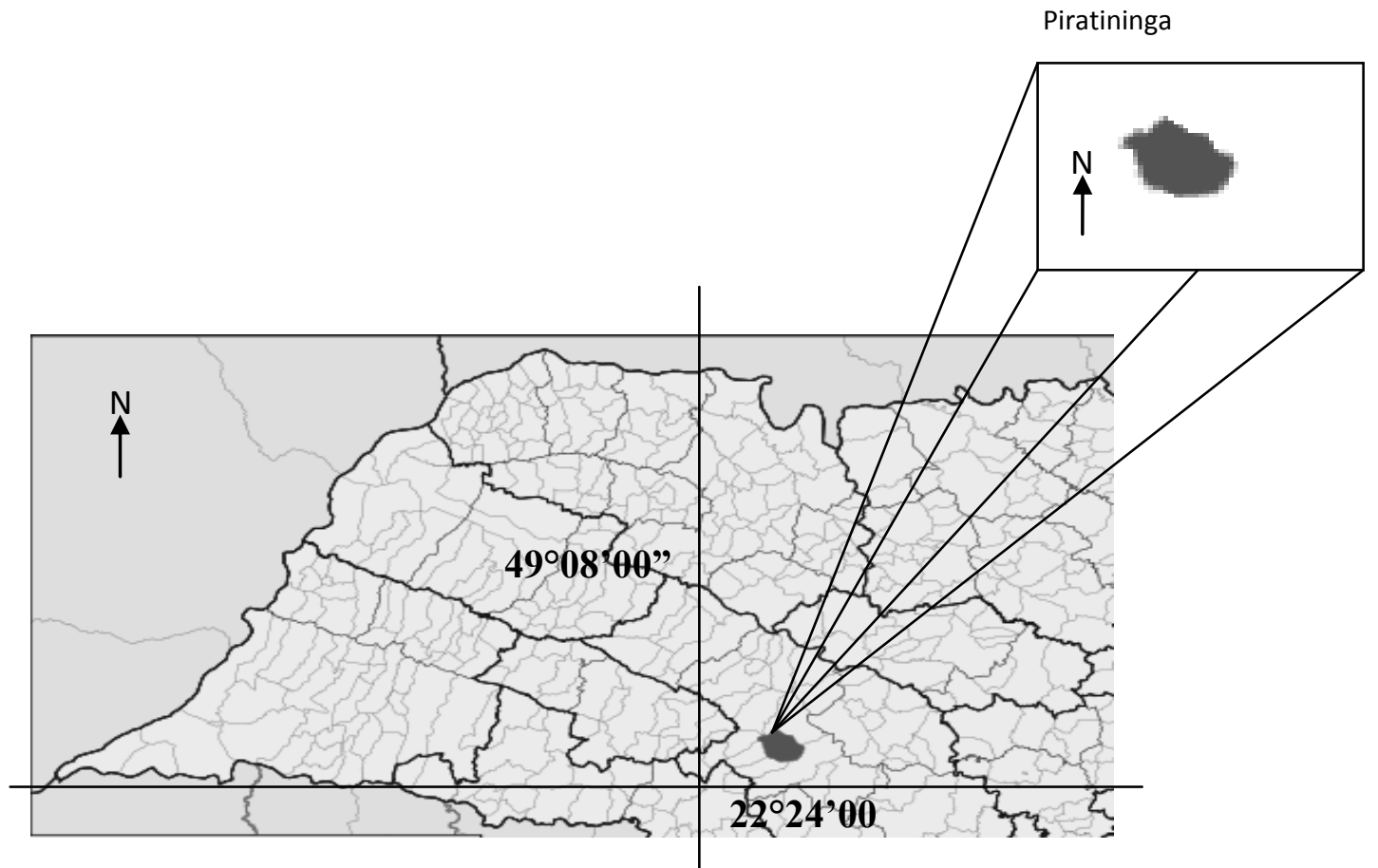

Figura 1. Localização do Município de Piratininga

A temperatura média anual é de $22,2^{\circ} \mathrm{C}$ com Max. de $30,6^{\circ} \mathrm{C}$ e min. $11,3^{\circ} \mathrm{C}$ a precipitação anual é de aproximadamente $1.317,1 \mathrm{~mm}$. (CEPAGRI, 2013)

A densidade demográfica de Piratininga, em 1996, conforme dados do IBGE, era de $25,7 \mathrm{hab} / \mathrm{km}^{2}$, cabendo à zona urbana $81,7 \%$ do total de habitantes, e apenas $18,3 \%$, para a zona rural, com um crescimento de 7,49\% o senso realizado em 2010 apresentou população estimada de 12.072 habitantes, um aumento de 30 hab $/ \mathrm{km}^{2}$ de densidade demográfica.

\subsubsection{Programas computacionais utilizados}

Para realização do trabalho foram utilizados os programas, Idrisi 15.0 Andes Edition, desenvolvido pelo Clark Labs@ for Cartographic Technology and Analysis como programa de sistemas de informação geográfica e o Autodesc para vetorização dos dados e o Google earth $\odot$ para criação dos polígonos dos setores.

\subsubsection{Obtenção de temperatura:}


Foram utilizados dados vetoriais da malha urbana e da delimitação de cada bairro do município que serão confeccionados no programa Autocad Map, usandose como base a imagem do Landsat 5.

As fases de pré-processamento, processamento e transformação dos níveis de cinza em temperatura aparente foram executados no programa de Sistema de Informação Geográfica (SIG) Idrisi 15.0 - Andes Edition.

\subsubsection{Obtenção de imagens:}

As imagens utilizadas do sensor TM (Thematic Mappper) a bordo no satélite Landsat 5. A banda 6 do infravermelho termal, para obtenção da temperatura de superfície. Todas as imagens correspondem à órbita 221 ponto 075 e 076.

As imagens foram adquiridas através da página de catálogo de imagens do Instituto de Pesquisas Espacias (INPE), referente às seguintes datas: 18/12/2012. As imagens foram escolhidas na estação correspondente a primavera, após um longo período de estiagem.

\subsubsection{Levantamento de áreas verdes e setorização do município:}

Os dados de arborização urbana e áreas verdes foram adquiridos através de mapa do município de Piratininga através da Prefeitura Municipal em levantamento realizado anteriormente. (Fernandes, et. al. 2011)

A divisão por setores seguirá a divisão demonstrada nos métodos.

\subsection{Métodos}

\subsubsection{Imagem}

Para a obtenção dos dados da temperatura aparente da superfície é necessário o pré-processamento das imagens. Esta etapa visa melhorar a qualidade dos 
dados, com o emprego de técnicas como: redução da dimensionalidade realce da imagem e retificação geométrica.

Primeiramente a cena imageada foi reduzida de modo a restringirse apenas à área de estudo, utilizando-se a ferramenta reformat menu (WINDOW) do Idrisi. Após, foi aplicado o realce com o intuito de melhorar a qualidade visual das imagens, isto é, para ampliar o contraste das feições da cena, utilizando-se da ferramenta image processing (STRETCH) para todas as bandas.

O município em estudo está representado em duas cenas de pontos diferentes da mesma órbita o que leva ao processamento de imagem através da opção mosaico, Figura 2 no programa Idrisi.
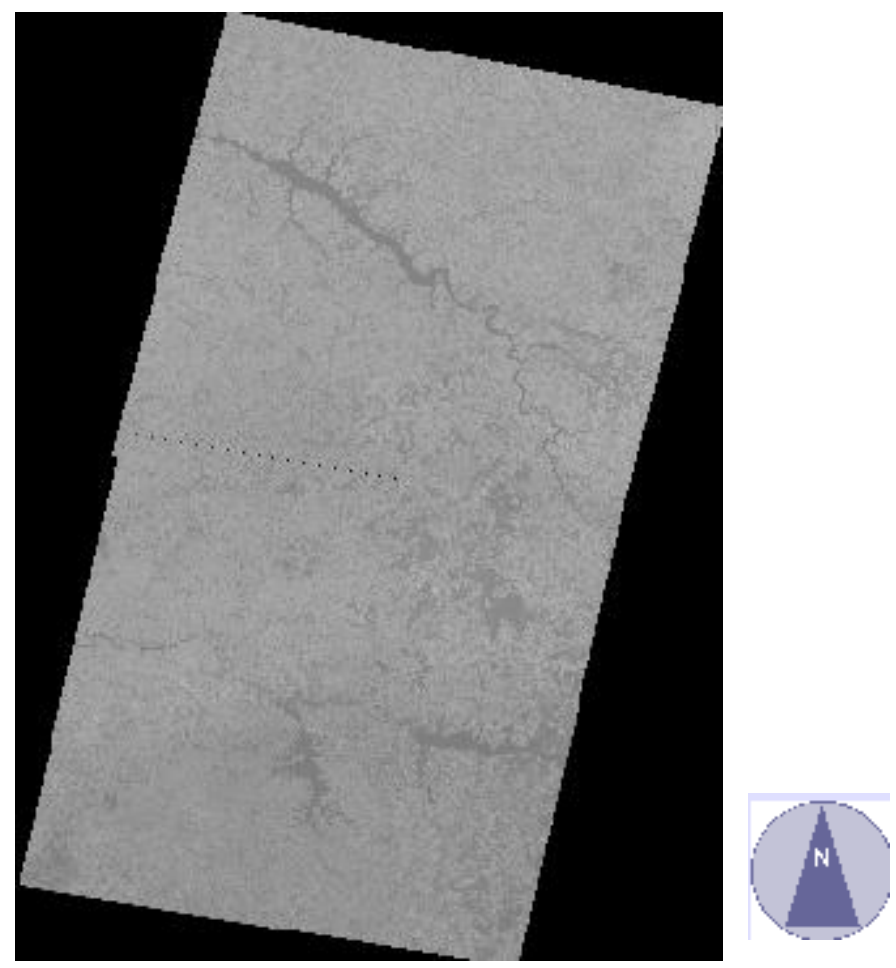

Figura 2. Imagem bruta do Mosaico dos pontos 75 e 76 da orbita 221 banda 6 .

Para correção dos erros contidos na imagem devido à movimentação do satélite e curvatura da Terra (projeção e sistema de referência) foi executada a retificação geométrica. Neste processo faz-se o registro, através das coordenadas geográficas, dos pontos de controle utilizando uma imagem previamente registrada, onde pontos devidamente identificados (georreferenciados) foram associados aos pixels da imagem de interesse. 
Todas as etapas são representadas de forma simplificada na Figura

3.

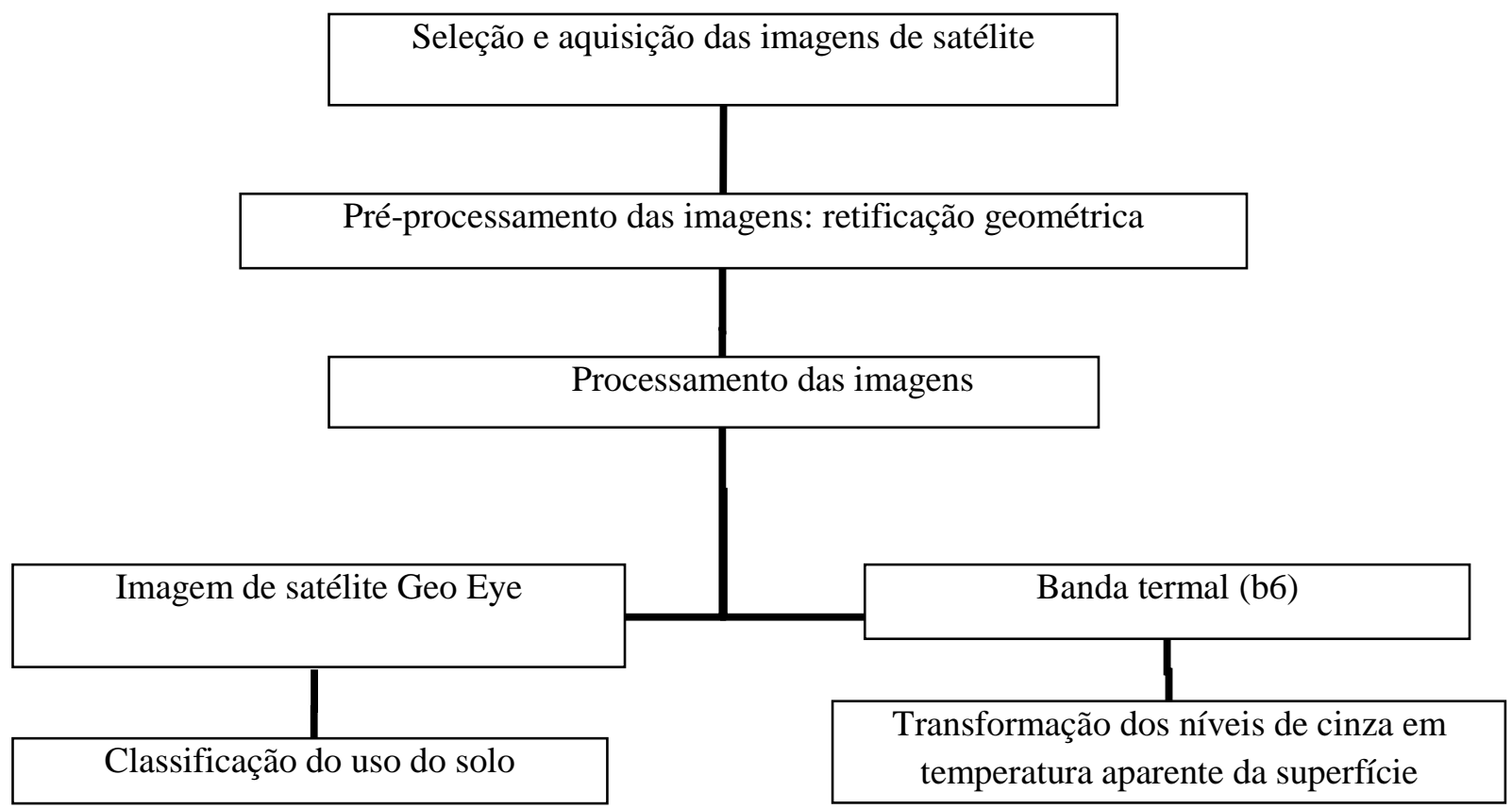

Figura 3. Fluxograma das etapas da metodologia.

\subsubsection{Temperatura aparente da superfície}

O algorítimo de transformação do DN para graus Celsius utilizado foi do programa Idrisi 15.0, devidamente validada por Coltri (2006), através das funções Image processing (TRANSFORMATION/ THERMAL).

Para encontrar as faixas intermediárias de níveis de cinza de cada imagem, foi feito um histograma da imagem. Para associar o DN ao seu respectivo pixel, as imagens da banda termal foram transformadas para o formato de arquivo ASCII, a fim de relacionar cada pixel com um valor de DN e associá-lo ao grau Celsius definido pelo algoritmo.

Os valores de temperatura das imagens foram submetidos a análise de variância a fim de verificar se os valores encontrados se diferem estatisticamente, caso sejam diferentes serão submetidos ao teste de Tukey, ao nível de 5\% para comparação de médias duas a duas. 


\subsection{3 Áreas verdes}

O mapa de áreas verdes e arborização urbana que foram utilizados estarão no formato Dwg para que seja feito o cruzamento de informações de temperatura e as áreas verdes com o objetivo de verificar se há influencia de mudança do micro-clima relacionado a essas áreas.

O mapa salvo em dwg foi aberto no AutoCAD para que haja a correção cartográfica, com referências geográficas e depois exportado para o Idrisi Selva Crack onde foi feito a sobreposição da imagem do mapa com a imagem de satélite com as bandas termais já definidas.

\subsubsection{Levantamento de temperatura em campo}

O levantamento de temperatura no município utilizando-se o thermohigrômetro Smart Sensor® modelo AR 837, realizado no dia 21/11/2012 com início as $14 \mathrm{~h} 30$ e término as $15 \mathrm{~h} 32$, que mostra as temperaturas mínimas e máximas $\left({ }^{\circ} \mathrm{C}\right)$ além da máxima umidade relativa do $\operatorname{ar}(\%)$ de 25 pontos distintos.

Os pontos foram escolhidos aleatoriamente em vários locais da cidade distantes entre si e atingiu toda a malha urbana.

\subsubsection{Classe de uso do solo}

A área do município foi classificada de acordo com o uso do solo, por meio de imagens de satélite obtidas pelo Google Earth.

Foram identificados 4 tipos de classe de interesse: Cultura de Eucalipto, Mata nativa, Área urbana e Solo exposto.

A classe área urbana sofre influência das atividades humanas o que altera o micro-clima, as classes cultura de eucalipto e mata nativa podem apresentar semelhante amplitude térmica, caso estejam no mesmo estágio de desenvolvimento. E a classe solo exposto apresenta a maior elevação térmica devido a área de exposição a radiação solar direta. 


\subsubsection{Divisão da malha urbana por setores}

A malha urbana do município foi dividida por setores, representado na Figura 4, tendo em vista os limites de bairros já conhecidos. Alguns bairros são relativamente pequenos, o que permitiu uni-los formando um único setor, conforme mostrado na Tabela 2.

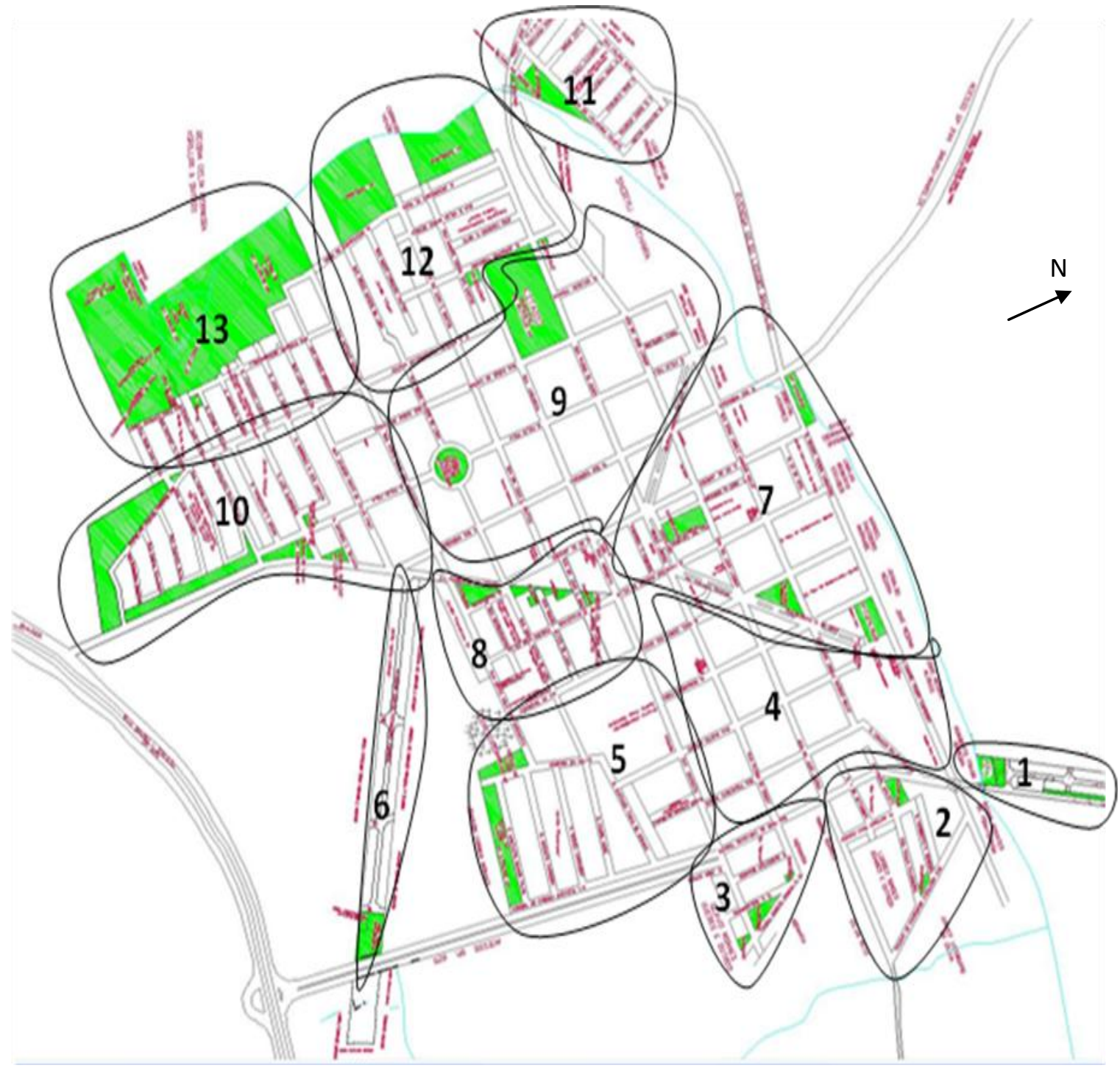

Figura 4. Mapa setorização. 
Tabela 2. Setores do Município de Piratininga.

\begin{tabular}{cl}
\hline SETOR & BAIRRO \\
\hline $\mathbf{1}$ & Parque Bela Vista \\
$\mathbf{2}$ & Vila Soares \\
$\mathbf{3}$ & Vila Moraes \\
$\mathbf{4}$ & Centro I \\
$\mathbf{6}$ & Jardim Panorama \\
$\mathbf{7}$ & Jardim Santo Antônio \\
$\mathbf{8}$ & Jd. Cel. Antonio da Cunha Castro, Jd Panorama II e Conj. Hab. "Padre Unsué \\
$\mathbf{9}$ & Verde" \\
$\mathbf{1 0}$ & Jd. Kirilos, Conj. Hab. "Dr. Antônio Ferreira do Espírito Santo" \\
$\mathbf{1 1}$ & Conj. Hab. "Luis Faustino de Souza”, Boa Vista I, II, III e IV e Conj. Hab. \\
$\mathbf{1 2}$ & Coj. Hab. “Amire Maluf” e Jardim Vilane \\
$\mathbf{1 3}$ & Conj. Hab. "Fernando Motta Mendes" e Jd. Santa Maria \\
\hline
\end{tabular}

\subsubsection{Tratamento dos dados}

A tabela de temperatura indicou em cada ponto respectivo do mapa, a temperatura levantada em campo com um termhigrômetro e a imagem de satélite mostrará a temperatura de superfície do dia 18/12/2012. Esses dados serão analisados a fim de sobrepor informações de áreas verdes, arborização urbana e ilhas de calor proporcionando assim a possibilidade de análise da atual situação e interferência desses dados na qualidade de vida da população. 


\section{RESULTADOS E DISCUSSÃO}

\subsection{Desempenho das ilhas de calor}

Após aplicação do algoritmo termal de transformação e processamento da imagem, obteve-se o comportamento da temperatura aparente do município de Piratininga do dia 18/12/2012, conforme representado na Figura 5.

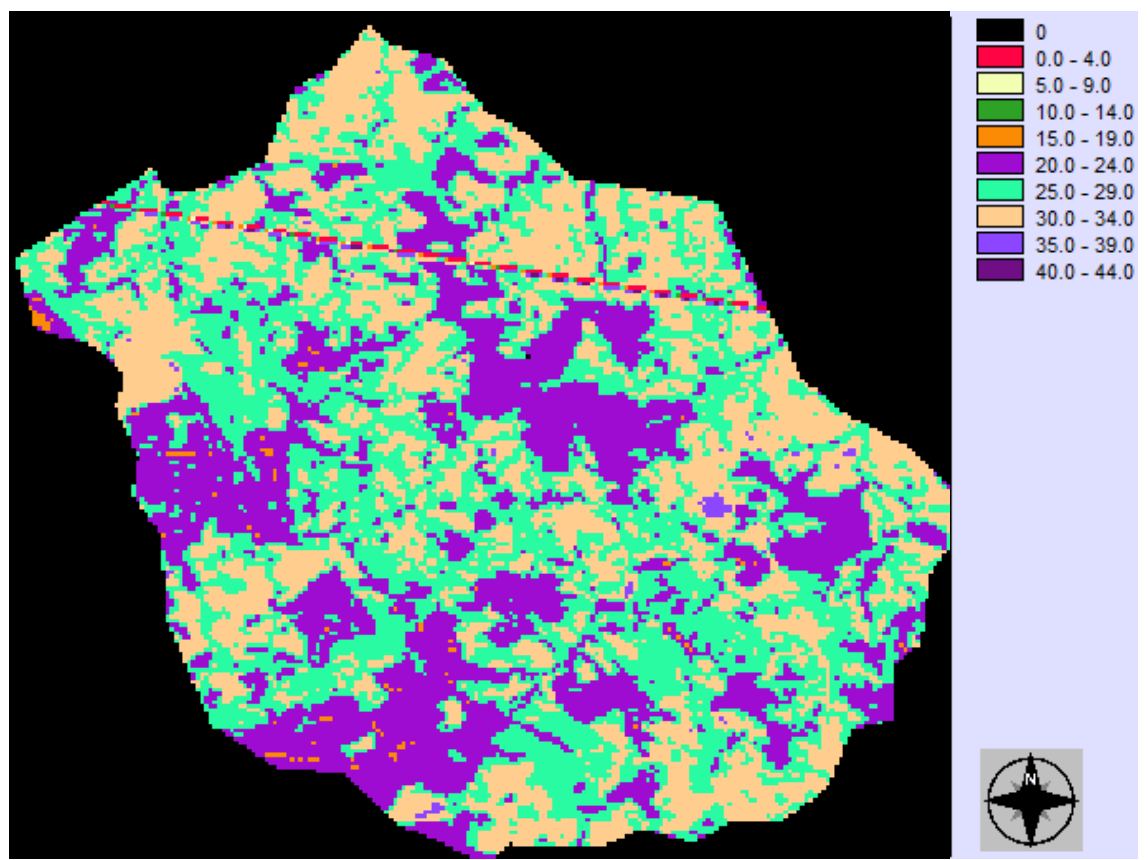

Figura 5. Temperatura aparente da superfície do Município de Piratininga. 
Foram identificadas 10 faixas de temperatura que variaram de $0.0^{\circ} \mathrm{C}$ a aproximadamente $44.0^{\circ} \mathrm{C}$. As temperaturas de $0.0^{\circ} \mathrm{C}$ a $4.0^{\circ} \mathrm{C}$ representado pela cor Pink foi registrada devido ao ruído resultante do processo de junção das imagens (mosaico).

O histograma (Figura 6) gerado a partir da imagem do município mostra que as temperaturas de $20.0^{\circ} \mathrm{C}$ a $34.0^{\circ} \mathrm{C}$ representados pelas colunas 5,6 e 7 são predominantes em todo o município.

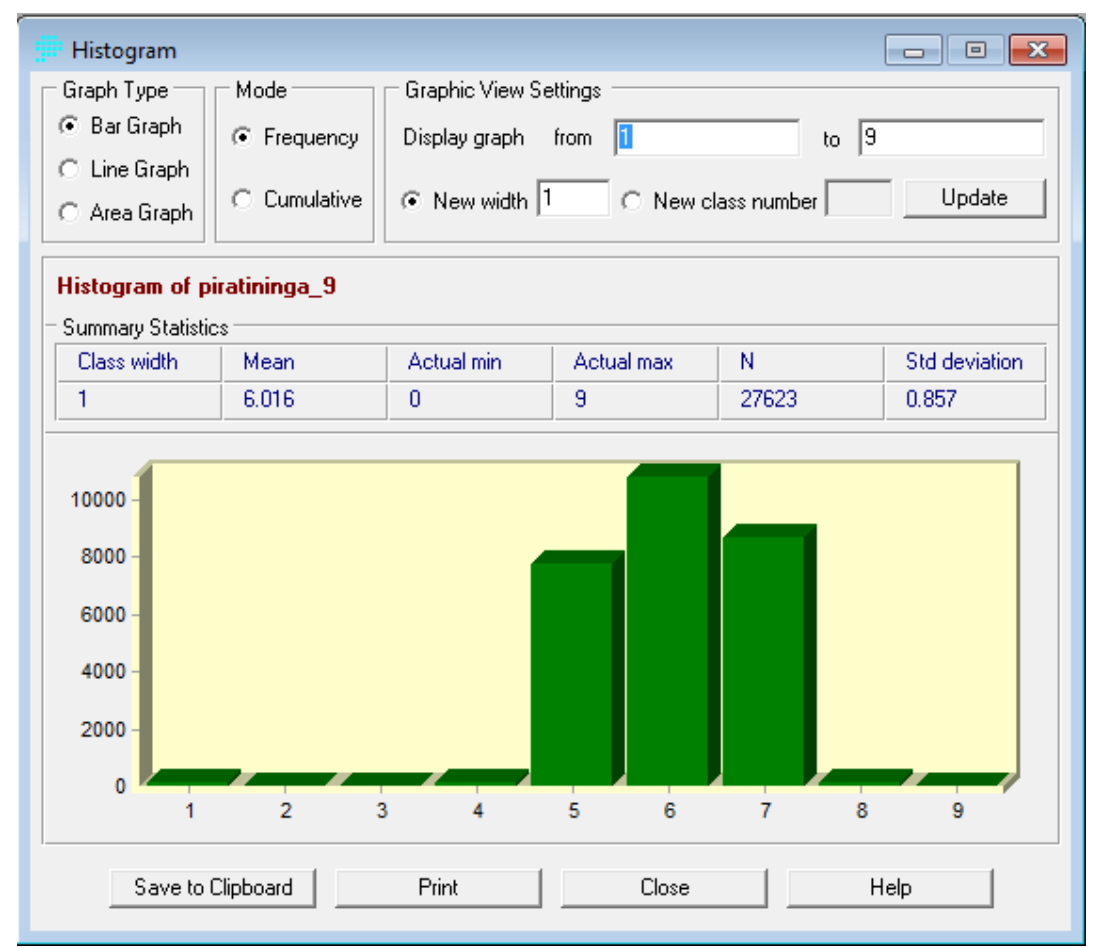

Figura 6. Histograma da temperatura aparente do Município.

No detalhe, a Figura 7 mostra a faixa de temperatura nos setores anteriormente definidos da área urbana, sobreposta á imagem da área, é possível observas que as temperaturas variam de $20^{\circ} \mathrm{C}$ (lilás) a $34^{\circ} \mathrm{C}$ (bege). 


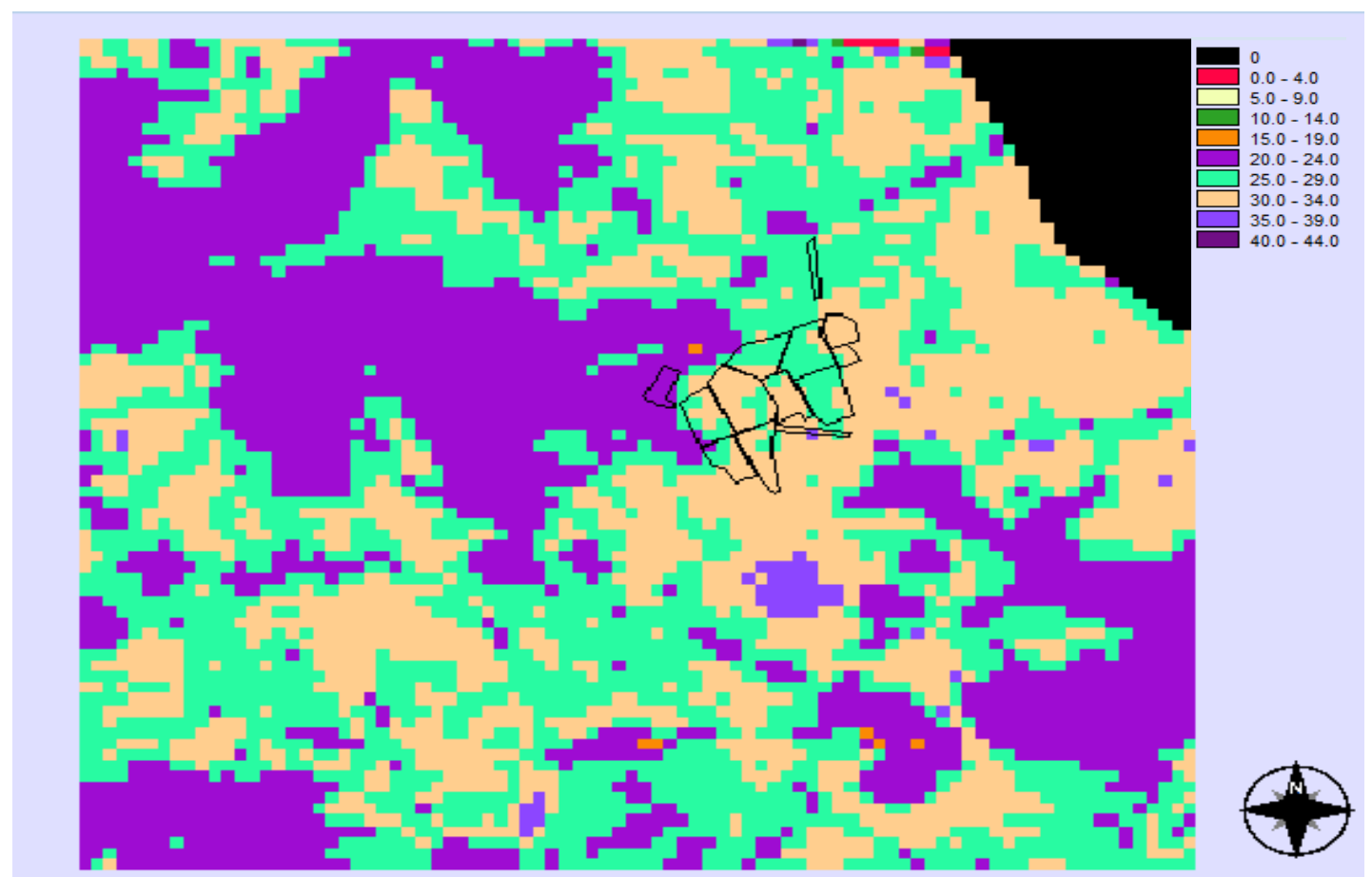

Figura 7. Polígono dos setores da área urbana do Município de Piratininga

\subsection{Classificação do solo e temperatura}

Pôde se identificar quatro classes representadas na Figura 8 e referenciadas na Tabela 3 .

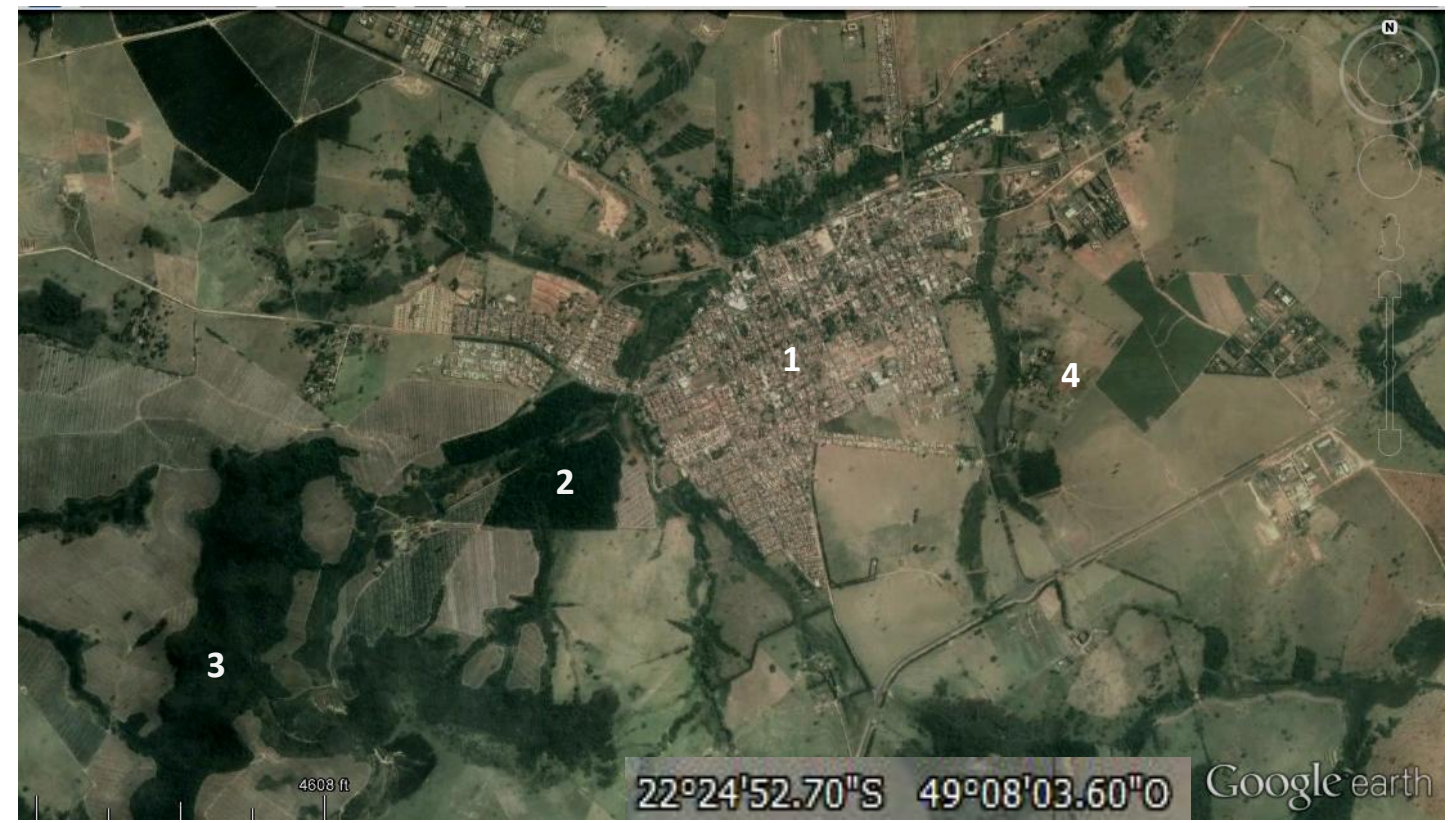

Figura 8. Classificação de uso do solo utilizando imagem do Geo Eye. 
Tabela 3. Coordenadas das classes de solo.

\begin{tabular}{cccc}
\hline Ponto & Coordenada x & Coordenada y & Classe \\
\hline $\mathbf{1}$ & $22^{\circ} 24^{\prime} 50^{\prime \prime}$ & $49^{\circ} 08^{\prime} 08^{\prime \prime}$ & Área urbana \\
$\mathbf{2}$ & $22^{\circ} 25^{\prime} 11^{\prime \prime}$ & $49^{\circ} 08^{\prime} 47^{\prime \prime}$ & $\begin{array}{c}\text { Cultura de } \\
\text { eucalipto }\end{array}$ \\
$\mathbf{3}$ & $22^{\circ} 25^{\prime} 38^{\prime \prime}$ & $49^{\circ} 09^{\prime} 44^{\prime \prime}$ & Mata nativa \\
$\mathbf{4}$ & $22^{\circ} 24^{\prime} 55^{\prime \prime}$ & $49^{\circ} 07^{\prime} 22^{\prime}$ & Solo exposto \\
\hline
\end{tabular}

\subsubsection{Classe área urbana}

Devido as diferentes épocas de ocupação do espaço urbano, é possível trabalhar por setores e detectar diferenças de temperatura resultante do tipo de edificação e intensidade de impermeabilização do solo.

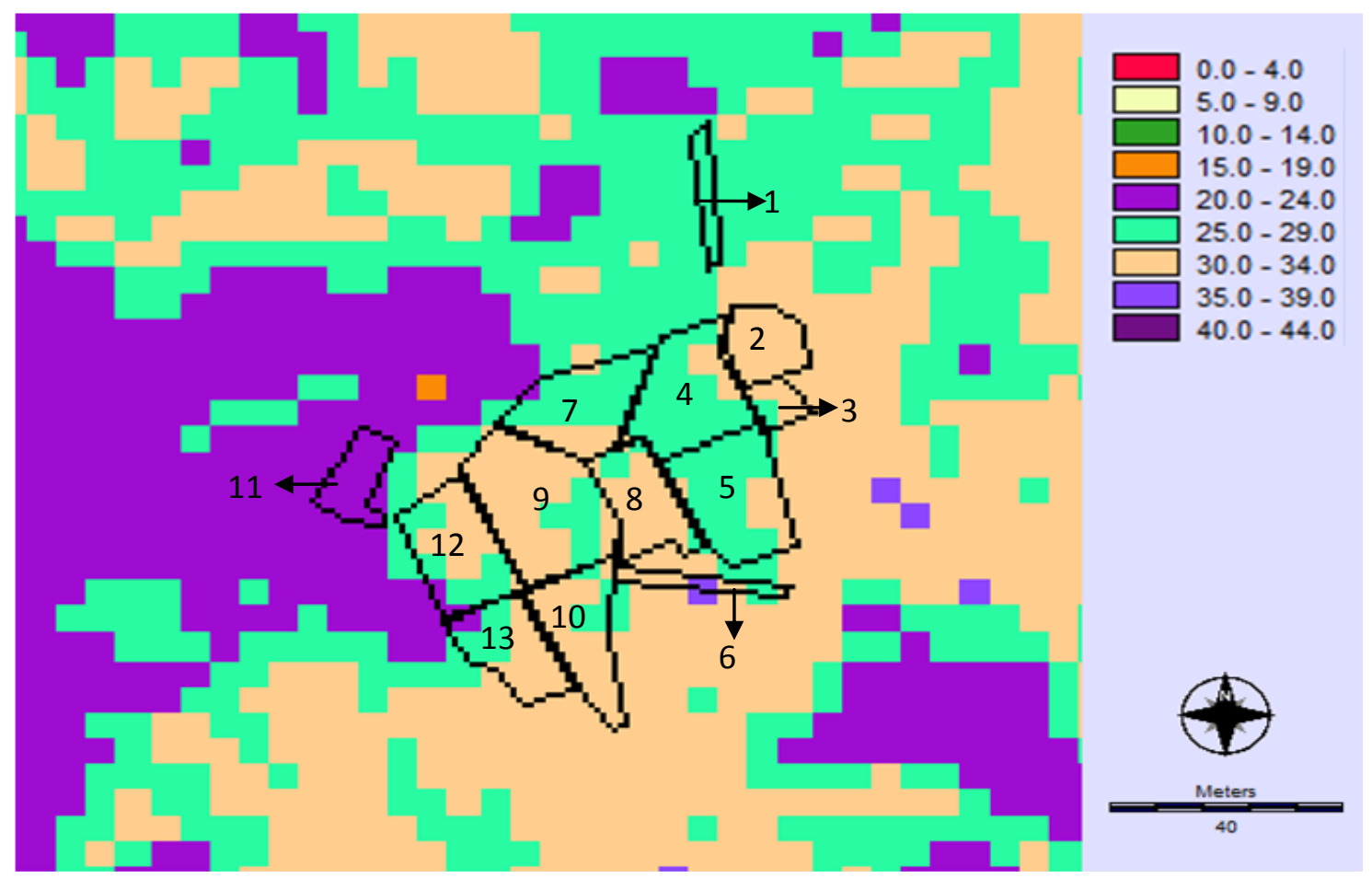

Figura 9. Detalhe da temperatura aparente da área urbana. 
Os setores 4, 5 e 7 são mais antigos e apresentam temperaturas em torno de $25.0^{\circ} \mathrm{C}$ a $29.0^{\circ} \mathrm{C}$ (Figura 9) esse padrão de temperatura é devido a arborização urbana, constituída de espécies arbóreas de grande porte com Índice de Cobertura Vegetal correspondente a metade do tamanho de área impermeável, como indicado na Tabela 4.

Tabela 4. Índice de Cobertura Vegetal

\begin{tabular}{ccc}
\hline Setor & $\mathbf{I C V}\left(\mathbf{m}^{\mathbf{2}}\right)$ & $\boldsymbol{\%}$ \\
\hline $\mathbf{4}$ & $56.130,769$ & 38,35 \\
$\mathbf{5}$ & $29.619,031$ & 33,82 \\
$\mathbf{7}$ & $29.619,031$ & 41,70 \\
\hline
\end{tabular}

ICV: Índice de Cobertura Vegetal

Fonte: Fernandes, 2011.

O setor 1 também apresenta temperatura variável entre $25.0^{\circ} \mathrm{C}$ a $29.0^{\circ} \mathrm{C}$ este caso ao contrário dos anteriormente citados é um bairro novo, porém sua área de cobertura vegetal é maior, segundo Fernandes et al (2011), pois muitos terrenos ainda não estão edificados e a população ainda é reduzida.

Analisando os setores 9, 10, 12 e 13 (Figura 9), podemos observar que a predominância é de temperaturas mais elevadas que estão entre $30.0^{\circ} \mathrm{C}$ a $34.0^{\circ} \mathrm{C}$. Isso ocorre devido ao grande número populacional da região que é ocupado em sua maior parte por moradia social. Os pontos de temperatura variável entre $25.0^{\circ} \mathrm{C}$ a $29.0^{\circ} \mathrm{C}$ dos mesmos setores ocorre devido a uma concentração da arborização representada por praças e áreas verdes.

A temperatura amena no setor 11 é devido a proximidade do plantio de eucalipto que ladeia todo o loteamento e por ser um bairro periférico, apresenta uma diferença de temperatura, como descrito por Lombardo (1985).

Outra análise que pôde ser feita na Figura 10 é possível observar que existe uma transição entre as áreas de temperaturas amenas e elevadas como se fosse um cinturão de forma a mesclar as temperaturas.

Os setores 4, 5 e 7 apresentam uma média de temperatura de $27,0^{\circ} \mathrm{C}$ sendo os setores com temperatura mais amena devido a área de cobertura vegetal.

A diferença de temperatura dentro nos setores 9, 10, 12 e 13 de $32.0^{\circ} \mathrm{C}$ para $27.0^{\circ} \mathrm{C}$ é devido a existência de áreas verdes como praças. 
O levantamento em campo realizado com pontos aleatórios demonstrados na Figura 10 mostra uma variação de temperatura em torno de $34,4^{\circ} \mathrm{C}$ a $36,6^{\circ} \mathrm{C}$, como demonstrado na tabela 5 .

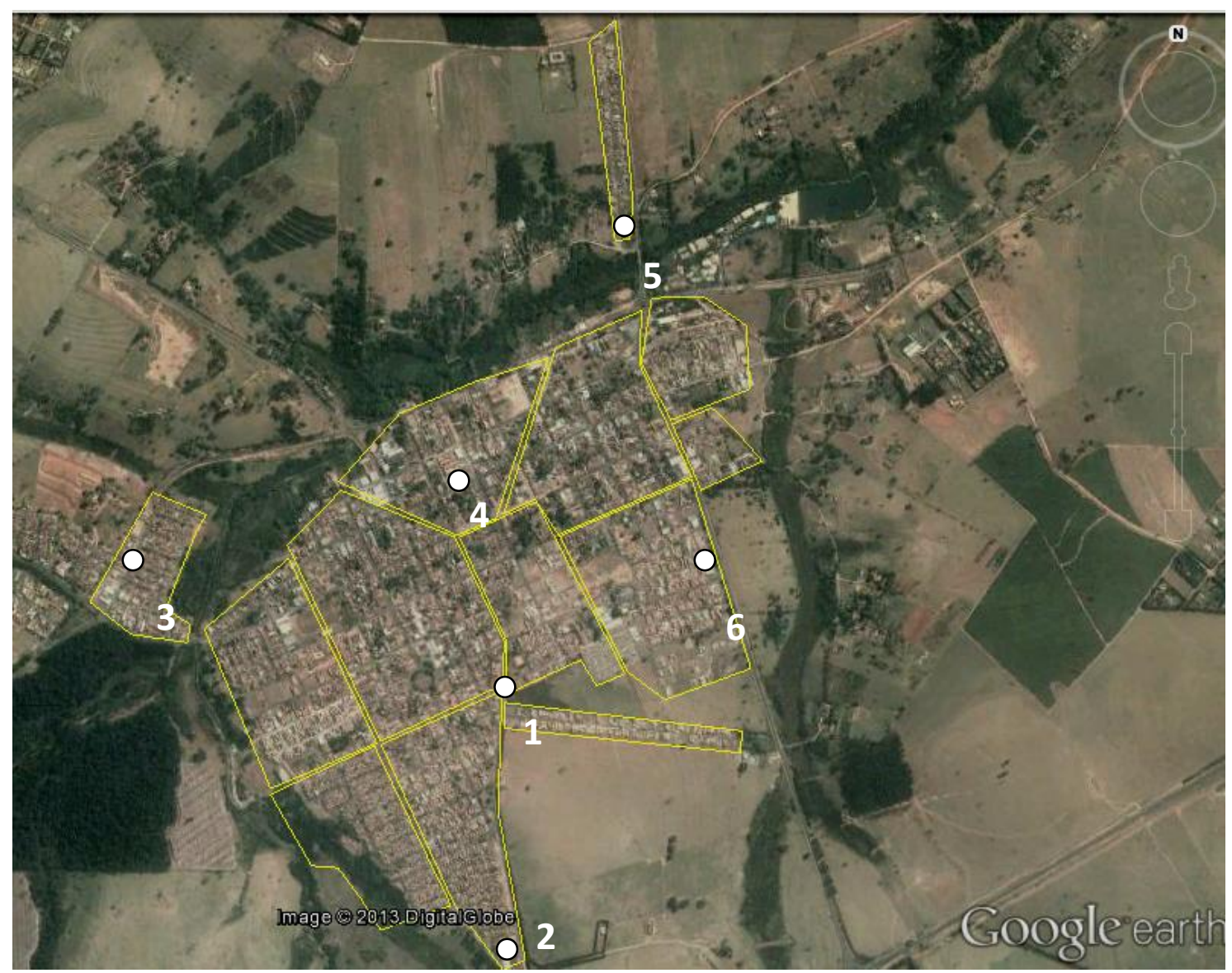

Figura 10. Pontos de levantamento de temperatura em campo.

Tabela 5. Levantamento com termo-higrômetro 21/11/2012

\begin{tabular}{cccc}
\hline Ponto & Coordenada X & Coordenada Y & Temperatura $\left({ }^{\circ} \mathbf{C}\right)$ \\
\hline $\mathbf{1}$ & $22^{\circ} 25^{\prime} 02^{\prime \prime}$ & $49^{\circ} 08^{\prime} 05^{\prime \prime}$ & 34,4 \\
$\mathbf{2}$ & $22^{\circ} 25^{\prime} 26^{\prime \prime}$ & $49^{\circ} 08^{\prime} 04^{\prime \prime}$ & 35,6 \\
$\mathbf{3}$ & $22^{\circ} 24^{\prime} 49^{\prime \prime}$ & $49^{\circ} 08^{\prime} 44^{\prime \prime}$ & 36,8 \\
$\mathbf{4}$ & $22^{\circ} 24^{\prime} 43^{\prime \prime}$ & $49^{\circ} 08^{\prime} 09^{\prime \prime}$ & 35,8 \\
$\mathbf{5}$ & $22^{\circ} 24^{\prime} 19^{\prime \prime}$ & $49^{\circ} 07^{\prime} 51^{\prime \prime}$ & 35,2 \\
$\mathbf{6}$ & $22^{\circ} 25^{\prime} 50^{\prime \prime}$ & $49^{\circ} 08^{\prime} 43^{\prime \prime}$ & 36,6 \\
\hline
\end{tabular}




\subsubsection{Classe eucalipto}

Na figura 11 podemos observar uma mancha na cor lilás com temperatura variável entre $20.0^{\circ} \mathrm{C}$ a $24.0^{\circ} \mathrm{C}$, essa área corresponde ao cultivo de eucalipto, a temperatura amena é devido a utilização da incidência da luz solar pelas folas nos processos biológicos como, por exemplo, a fotossíntese.

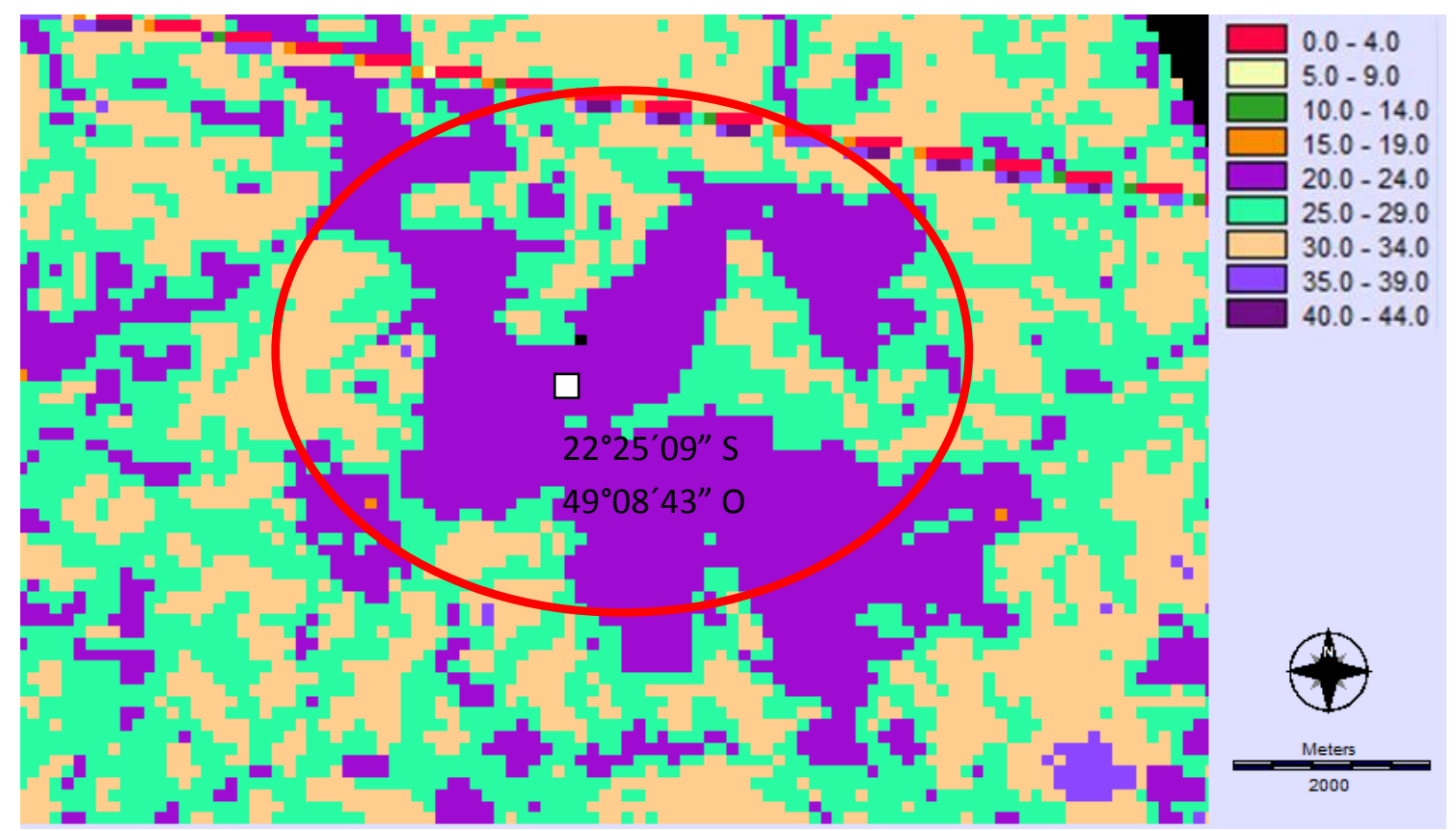

Figura 11. Ponto da classe eucalipto.

\subsubsection{Classe mata nativa}

A área de mata nativa representada pela cor lilás, na Figura 12, se mistura com a vegetação de cultivo de eucalipto por estarem próximas e apresentarem a mesma temperatura aparente. Essa igualdade de temperatura se deve a homogeneidade da vegetação que se encontra em estado tardio de regeneração, estando com o desempenho físico-químico em total desempenho há um maior aproveitamento da incidência de radiação solar, bem como na cultura de eucalipto que por possuir plantio uniforme e de mesma idade. 


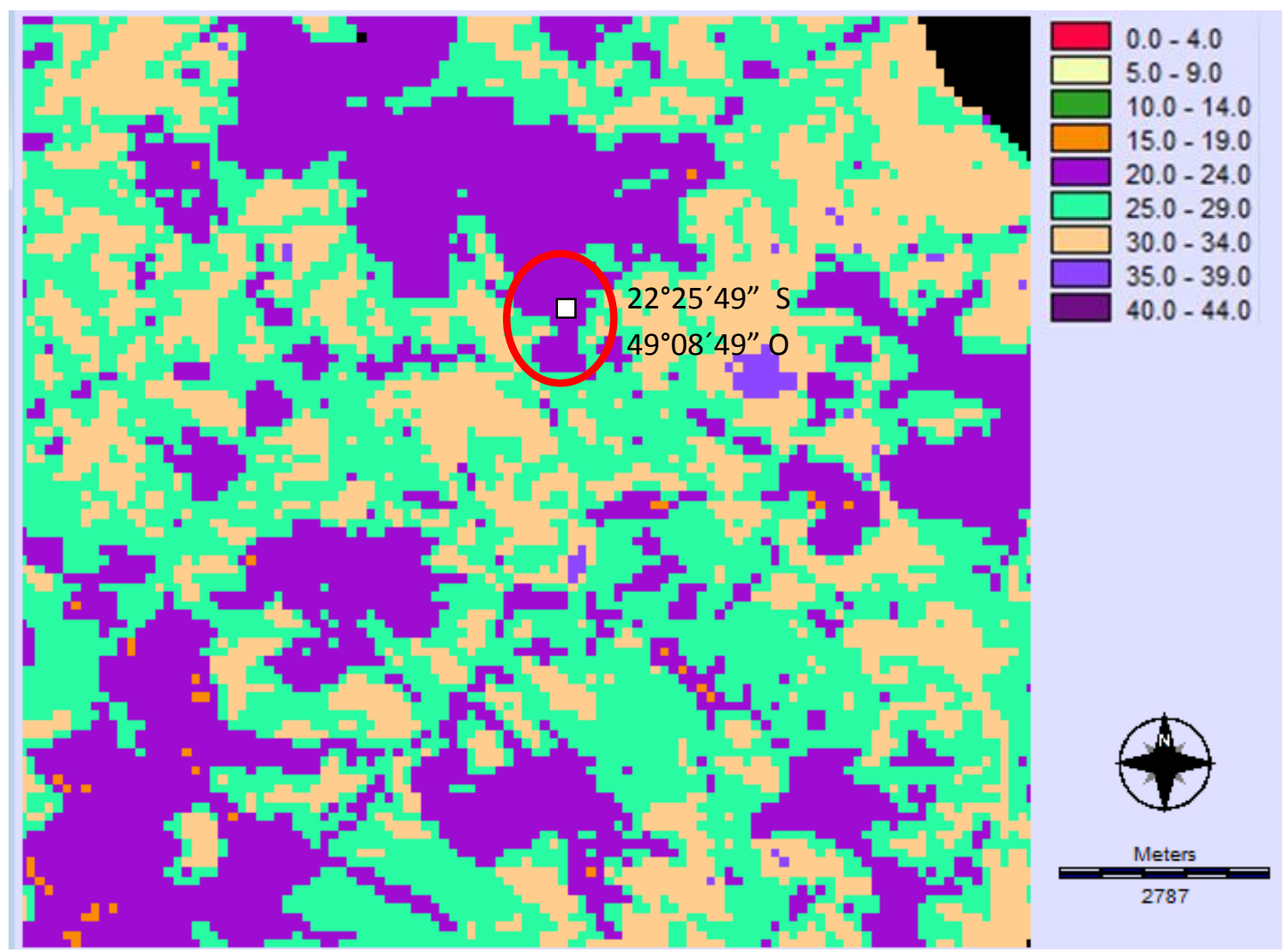

Figura 12. Ponto da classe mata nativa

\subsubsection{Classe solo exposto}

Na Figura 13 podemos observar a mancha azulada que representa o solo exposto, com temperatura variável entre $35.0^{\circ} \mathrm{C}$ e $39.0^{\circ} \mathrm{C}$, assim como no trabalho realizado por Mashiki (2012), que encontrou valores bem próximos ao citado numa área de solo exposto no Município de Botucatu.

Entre as classes estudas a classe cultivo de eucalipto e mata nativa apresentaram temperatura aparente amena em torno de $22.0^{\circ} \mathrm{C}$ e o solo exposto onde há maior temperatura aparente este valor apresenta uma média de $37.0^{\circ} \mathrm{C}$. 


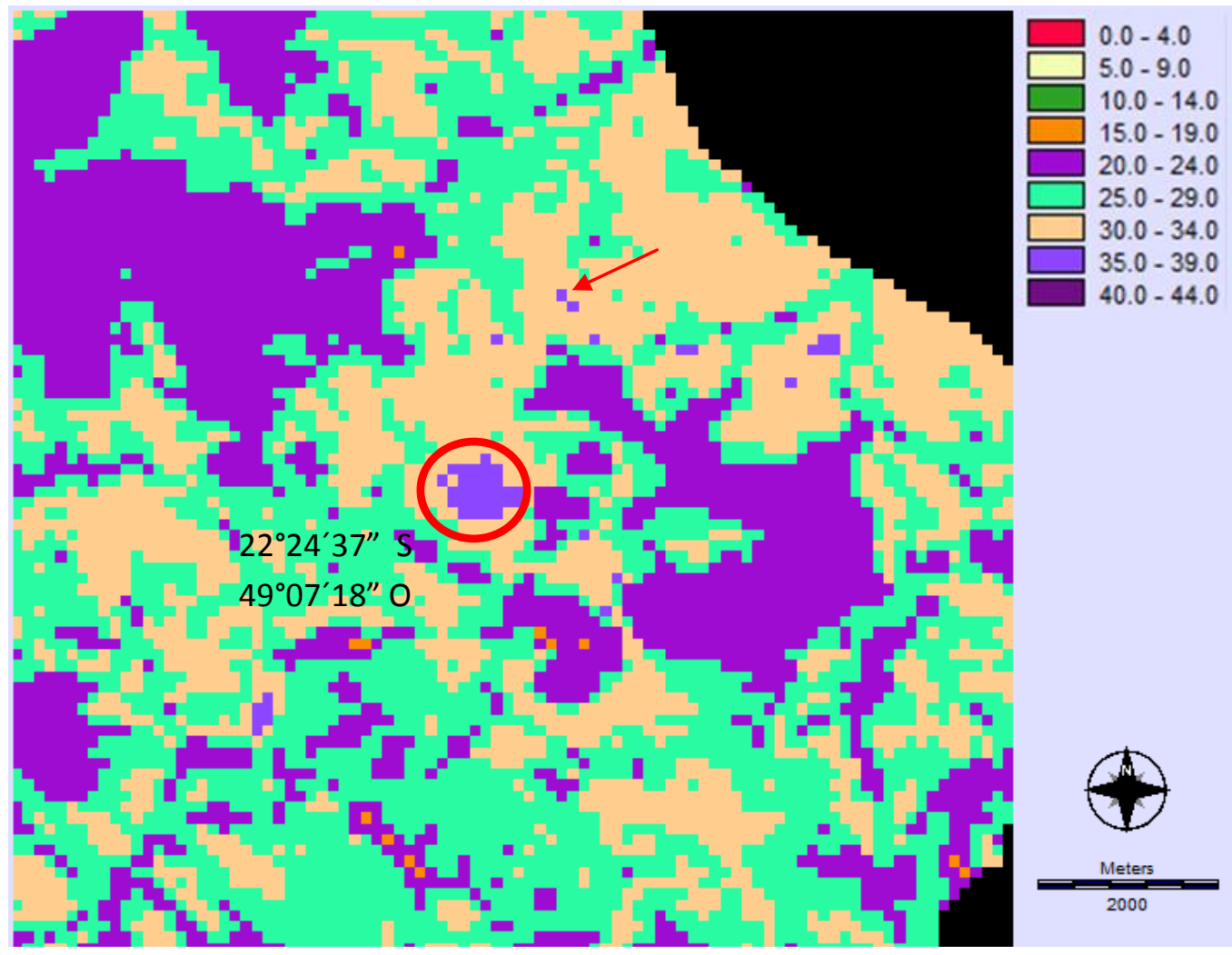

Figura 13. Detalhe da classe solo exposto.

Essa temperatura elevada é possível devida a falta de cobertura do solo o que proporciona um aquecimento rápido no período de exposição a radiação solar. 


\section{CONCLUSÕES}

O sensoriamento remoto e o sistema de informação geográfica permitem a avaliação de diferentes temperaturas da superfície terrestre.

A área reduzida do Município e a baixa resolução do sensor utilizado dificultaram a análise de temperatura da área urbana sendo necessário o uso de outros programas para auxiliar na interpretação de dados.

A cobertura de vegetação na área urbana interfere diretamente na diminuição da temperatura melhorando o micro-clima urbano.

As diferentes coberturas da superfície analisada também interferem na temperatura aparente.

O governo municipal precisa planejar uma forma de ampliação da cobertura verde.

As altas temperaturas do levantamento em campo com termohigrômetro na área urbana, em média de $35.0^{\circ} \mathrm{C}$ é devido ao clima que seco e a ausência de vento além da rugosidade e edificação da superfície.

Com as análises dos resultados recomenda-se que a área de cobertura vegetal seja aumentada e que de forma homogênea ocupe toda a malha urbana. 


\section{REFERÊNCIA BIBLIOGRÁFICA}

ALMEIDA, A. L. B. dos S. de S. S. L.. Arvores e floresta urbana: condições que a cidade oferece. In: O valor das árvores: Arvore e floresta urbana de Lisboa. Tese (Doutorado em arquitetura Paisagista) - Instituto Superior de Agronomia. Lisboa. 2006. p. 5-45.

ALMEIDA, D. N. de. Analise da arborização urbana de cinco cidades da região Norte do Estado de Mato Grosso. 62 p. Dissertação (Mestrado em Ciências Florestais e Ambientais) - Universidade Federal de Mato Grosso - Cuiabá - MT. 2009.

ANDRADE, T. O. Inventário e análise da arborização viária da Estância Turística de Campos de Jordão, SP. Piracicaba. 2002. 85f. Dissertação (Mestrado em Agronomia, Área de Concentração: Fitotecnia) - Escola Superior de Agricultura Luiz de Queirós. Universidade de São Paulo. 2002.

ANTUNES, P. de B. Competência constitucional em matéria ambiental e Zoneamento. In: Direito Ambiental. Ed. 6ª Rio de Janeiro: Lúmen Júris LTDA. 2002. Caps. III e VI, p. 77-92 e 181 - 194. 
BADIRU, A. I. PIRES, M. A., RODRIGUEZ, A. C. M. Método para classificação tipológica da floresta urbana visando o planejamento e a gestão das cidades. Anais XII Simpósio Brasileiro de Sensoriamento Remoto. Goiânia. Brasil. 2005. INPE. p. 1427 1433.

BADIRU, A. I. Floresta urbana: uma proposta metodológica no estudo do espaço hídrico e da configuração territorial de registro, região do vale do Ribeira-SP. 200f. Tese (doutorado em tecnologia nuclear). Instituto de Pesquisas Energéticas e Nucleares. Universidade de São Paulo. 2006.

BARBIRATO, G.M.; SOUZA, L.C.L.; TORRES, S.C. Clima e cidade: a abordagem climática como subsídio para estudos urbanos. Macéio: EDUFAL, 2007. 164 p.

BARBOSA, A.P. Comparação de métodos de classificação de imagens, visando o gerenciamento de áreas citrícolas. 2009. Dissertação (Mestrado em Agronomia)Faculdade de Ciências Agronomicas, Universidade Estadual Paulista, Botucatu, 2009.65f.

BORBA, M. de C. et. Al. A informática em ação: formação de professores, pesquisa e extensão. São Paulo: Ed olho d’agua. 2000. 80 p.

Brasília. Lei Federal $\mathrm{n}^{\circ} 10257$ de 10 de julho de 2001. Disponível em: < http://www.planalto.gov.br/ccivil/leis/LEIS_2001/L10257.htm>. Acesso em $11 \mathrm{dez} 2011$.

CAPRON, H. L. JOHNSON, J. A. Introdução a informática. São Paulo: Ed Person Prentice Hall Brasil. Ed. 1 ${ }^{\text {a }}$ 2004. 350p.

CEPAGRI, Centro de Pesquisas Meteorológicas e Climáticas Aplicadas a Agricultura. A CLASSIFICAÇÃO CLIMÁTICA DE KOEPPEN PARA O ESTADO DE SÃO PAULO. Disponível em: <http://www.cpa.unicamp.br/outras-informacoes/clima-dosmunicipios-paulistas.html>, acesso em 13 jun 2013. 
COLTRI, P.P. Influência do uso e cobertura do solo no clima de Piracicaba, São Paulo: Análise de séries históricas, ilhas de calor e técnicas de sensoriamento remoto. Piracicaba. 2006. 166p. Dissertação (Mestrado em Agronomina/Fitotecnia). Escola Superior de Agronomia Luiz de Queiroz/USP.

COLTRI, P.P; VELASCO, G.N. POLIZEL, J.L.; DEMETRIO. V.A.;FERREIRA, N.J. Ilhas de Calor da estação de inverno da área urbana do município de Piracicaba, SP. In: SIMPÓSIO BRASILEIRO DE SENSORIAMENTO REMOTO, 13, 2007. Florianópolis. Anais... São José dos Campos: INPE, 2007. p. 5151-5157.

COSTA, D.F.; PERES, L.F.; SILVA, H.R. Identificação de ilhas de calor na área urbana de Ilha Solteira-SP através da utilização de geotecnologias. In: SIMPÓSIO BRASILEIRO DE SENSORIAMENTO REMOTO, 14, 2009. Natal. Anais... São José dos Campos: INPE, 2009. p. 647-653.

CROFT, A.R.; BAILEY R.W. Mountain Water. USDA. Forest Service. Intermountain Region, 1964. 64 p.

CROSTA, Á. P. Processamento Digital de Imagens de Sensoriamento Remoto. Ed. Rev. Campinas, SP: IG/UNICAMP, 1993.

FADIGAS, L. S. A Natureza na Cidade, uma perspectiva para a sua integração no tecido urbano. 116f. Tese (Doutoramento em planejamento urbanístico). Faculdade de Arquitectura. Universidade Técnica de Lisboa. Lisboa. 1993.

FERNANDES, N. M. S.; CAMPOS, S.; MOREIRA K. F.; PISSARRA, T. C. T.; RODRIGUES, F. M.; Análise do índice de cobertura vegetal da área urbana de Piratininga (SP), Revista Ciência Geográfica, Bauru, Vol. XV, Jan/Dez. Pág. 78 - 83, 2011.

FIALHO, E. S. Ilha de Calor em cidade de pequeno porte: Um caso de Viçosa, Zona da Mata Mineira. São Paulo, 2009. 259p. Tese (Doutorado em Geografia/Geografia física) - Universidade de São Paulo. 
FLORENZANO, T. G. Imagens de Satélite para Estudos Ambientais. Oficina de Textos, São Paulo, 2002.

GARTLAND, L. Ilhas de calor: Como mitigar zonas de calor em áreas urbanas. São Paulo: Oficina de textos, 2010. 248p.

GIBAS, C. e JAMBECK, P. A biologia na era da informática. In: Desenvolvendo Bioinformática: ferramentas de software para aplicações em biologia. Tradução por Cristina de Amorim Machado. Rio de Janeiro. Ed. Campus. 2001. Cap. 01, p. 03-21.

GUALTIERI, A. ROMANO, Bernardino. Appennines settlement evolution and transformation analysis with GIS instrument. In: Anais European Regional Science Association Congress 45. p. 23-27. Aug. 2005. Amsterdam - Holanda.

HARDER, I. C. F. Inventário quali-quantitativo da arborização e infra-estrutura das praças da cidade de Vinhedo, SP . Piracicaba, 2002. 140f. Dissertação (Mestrado em Agronomia , áreas de concentração Fitotecnia) - Escola Superior de Agricultura Luiz de Queirós, Universidade de São Paulo, 2002.

HARVEY, D. The urbanization of capital. Baltimore: Johns Hopkins University Press, 1985. $239 \mathrm{p}$.

IBGE - Instituto Brasileiro de Geografia e Estatística. Disponível em www.censo2010.ibge.gov.br Acesso em 22 nov 2011.

IPEMET, Instituto de Pesquisa Meteorológica. Disponível em www.ipemet.unesp.br. Acessado em 10 jan 2012.

JORGENSEN, E. Towards an urban forestry concept: in Commonwealth Forestry Conférence. Ottawa: Canada Forestry Service. 1974. 
JUNIOR, O. P. M. Arborização urbana e Qualidade de vida. 2009. Disponível em: <http://www.ida.org.br/artigos/37-meioambiente/57-arborizacaourbana?format=pdf $>$ acesso em 12 abr 2011.

KONIJNENDIJK, C. C. A decade of urban forestry in Europe. In: Forest Policy and Economics $5.2003 . \quad$ p. 173-186. Disponível em: <http://www.treecanada.ca/programs/urbanforestry/cufn/Resources_Canadian/Konijnendij k\%202003_A\%20Decade\%20of\%20UF\%20in\%20Europe.pdf>. acesso em: 29 nov. 2012.

LEITE, M. A. F. P. Destruição ou descontração? 1ª Ed. São Paulo: Hucitec, 1994. 117 p.

LOMBARDO, M. A. Ilha de Calor nas metrópoles: o exemplo de São Paulo. São Paulo: Editora Hucitec, 1985. 244p.

LORENZI, H. Árvores Brasileiras: manual de identificação e cultivo de plantas arbóreas nativas do Brasil. v.1 e 2. São Paulo: Plantarum, 1998. 384 p.

MAGALHÃES, M. R. Espaços verdes urbanos. DGOT, Direção-Geral do Ordenamento do Território, Ministério do Planejamento e da Administração do Território, Lisboa, 1992. p. 10 e 11

MASHIKI, M. Y.; Geoprocessamento na identificação de ilhas de calor e influência do uso e ocupação do solo na temperatura aparente da superfície no município de Botucatu/SP. 2012. 80f. Dissertação (mestrado em Energia na Agricultura). Botucatu, 2013.

MENEGHETTI, G. I. P. Estudo de dois métodos de amostragem para inventário da arborização de ruas dos bairros da orla marítima do município de Santos, SP. Piracicaba, 2003. 73f. Dissertação (Mestrado em Recursos Florestais, opção Silvicultura e Manejo Florestal) - Escola Superior de Agricultura Luiz de Queirós, Universidade de São Paulo, 2003. 
METZGER, J. P. O que é ecologia de paisagens?. Biota Neotropica. v.1 n.1/2. dez. 2001. Disponível em: <http://www. biotaneotropica.org.br.htm>. Acesso em: 06 de jun 2012

MILANO, M. S. Avaliação quali-quantitativa e manejo da arborização urbana: o caso de Maringá. PR. 1988. 120f. Tese (Doutorado em Engenharia Florestal) . Setor de Ciências Agrárias, Universidade Federal do Paraná, Curitiba, 1988.

MÓDULO, M. Revista Nova Escola. Mat: O que é inteligência artificial? Onde ela é aplicada?. São Paulo: Ed Abril. Junho 2009. Disponível em: <http://revistaescola.abril.com.br/ciencias/fundamentos/inteligencia-artificial-onde-elaaplicada-476528.shtml> acesso em 20 ago 2011.

OKE, T.R. Techinical note n.134: Review of urban climatology. World Metereological Organization. Geneva, WMO, 1974. p.168-1973.

PREFEITURA MUNICIPAL DE PIRATININGA. Aspectos gerais. Piratininga, 1998. Disponível em: $<$ http://www.piratininga.sp.gov.br/template.php?pagina=showCidade.php\&id=10>. Acesso em: 02 mai 2012.

PRIMAVESI, O.; ARZABE, C.; PEDREIRA, M.S.; Mudanças climáticas: visão tropical integrada das causas, dos impactos e de possíveis soluções para ambientes rurais ou urbanos. São Carlos: Embrapa Pecuária Sudeste, 2007. - (Embrapa Pecuária Sudeste. Documentos, 70). Disponível em:

$<$ http://www.cppse.embrapa.br/servicos/publicacaogratuita/documentos/Documentos70pdf /view>. Acesso em 21 ago 2012.

SANTOS, N.R.Z.; TEIXEIRA, I.F. Arborização de vias públicas: ambiente x vegetação. Instituto Souza Cruz, 2001. 
SCHWATZMAN, S. et. Al. Inteligência Artificial In: Ciência e Tecnologia no Brasil: A capacitação brasileira para a pesquisa científica e tecnológica. $1^{\text {a }}$ Ed. Rio de Janeiro: Fundação Getúlio Vargas, 1996. p.263 - 286

SEgAWA, H. Ao Amor do Público: Jardins no Brasil. São Paulo: Studio Nobel. FAPESP. 1996. 256 p.

SILVA FILHO, D. F. da; PIVETTA, K. F.L.; COUTO, H.T. Z.; POLIZEL, J.L., Indicador de floresta urbana a partitr de imagens aéreas multiespectrais de alta resolução. Scientia Forestalis, nº 67, pág. 88-100, Abr. 2005, IPEF

SOMMERVILLE, I. Engenharia de sistema com base em computadores In: Software Engineering, Tradução por André Maurício de Andrade Ribeiro. $6^{a}$ edição. São Paulo: Pearson Addison Wesley, 2005. Cap. 2, p. 17 - 31.

TEIXEIRA, I. F. Análise quantitativa da arborização de ruas do conjunto habitacional Tancredo neves, Santa Maria, RS. Revista Ciência Florestal, Santa Maria. v.9, n.2, p. 921. 1999. 